of

\title{
Highly Integrated Nano-Platform for Breaking the Barrier between Chemotherapy and Immunotherapy
}

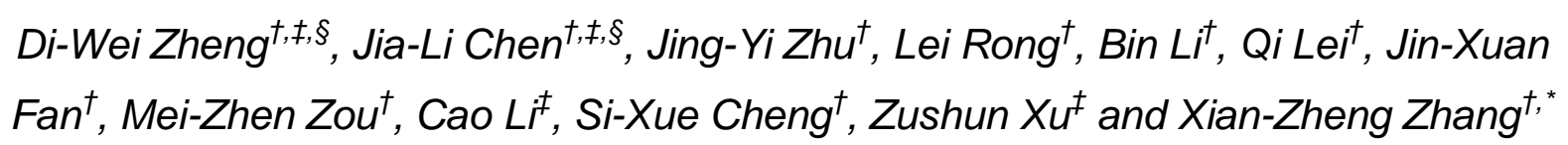

$\dagger$ Key Laboratory of Biomedical Polymers of Ministry of Education, Institute for Advanced Studies (IAS), Department of Chemistry, Wuhan University, Wuhan 430072, P. R. China

$\ddagger$ Hubei Collaborative Innovation Center for Advanced Organic Chemical Materials, Key Laboratory for the Green Preparation and Application of Functional Materials of Ministry of Education, Hubei University, Wuhan, Hubei 430062, P. R. China

* Corresponding author. Tel.: 86276875 5993; Fax: 862768754509.

E-mail address: XZ-zhang@whu.edu.cn (X.Z. Zhang).

$\S$ These two authors contributed equally to this work. 


\section{Experimental Section}

Materials. $\beta$-Cyclodextrin $(\beta-C D), p$-methyl benzene sulfonic chloride $(p$-TsCl), acetone, methanol, trimethylamine (TEA), dimethyl formamide (DMF), sodium hydroxide $(\mathrm{NaOH})$, hydrochloric acid $(\mathrm{HCl})$, ethylsilicate (TEOS), hexadecyl trimethyl ammonium bromide (CTAB), toluene, ethyl acetate, and hydrofluoric acid were purchased from Shanghai Reagent Chemical Co. (China). Ethanediamine (EDA), tetrabutylammonium iodide, ethylene diamine tetraacetic acid (EDTA), amidotrizoic acid, 3-chloropropyltriethoxysilane, 1H-Benzimidazole-5-carboxylic acid, diamine polyethylene glycol $\left(M_{w}=1000\right)$ and ferrocenecarboxylic acid were purchased from $\begin{array}{llll}\text { Aladdin Industrial } & \text { Corporation. } & \text { Tri-tert-butyl }\end{array}$ 1,4,7,10-tetraazacyclododecane-1,4,7,10-triacetate (t-Bu-DOTA) was purchased from $\begin{array}{llll}\mathrm{TCl} & \text { (Shanghai) Development } \quad \text { Co., }\end{array}$ Benzotriazol-1-yl-oxytripyrrolidinophosphonium hexafluorophosphate (PyBOP), $\mathrm{N}$-Hydroxybenzotriazole (HOBt), and $\mathrm{N}, \mathrm{N}$-diisopropylethylamine (DIEA) were purchased from Glbiochem (Shanghai) Ltd. Toluene, DMF and TEA were redistilled before used. Doxorubicin hydrochloride (DOX) was purchased from Zhejiang Hisun Pharmaceutical Co. (China). Other reagents were purchased from Shanghai Reagent Chemical Co. (China) and used as received.

General Characterization. ${ }^{1} \mathrm{H}-\mathrm{NMR}$ spectra were recorded on a Mercury VX-300 spectrometer (Varian) by using $\mathrm{D}_{2} \mathrm{O}$ and DMSO- $\mathrm{d}_{6}$ as solvents. Transmission electron microscopy (TEM) images were observed on a JEM-2100 (JEOL) transmission electron microscope. Confocal laser scan microscope (CLSM) images were obtained on a C1-Si (Nikon) confocal laser scan microscope. Fourier transform-infrared spectroscopy (FT-IR) was detected by a Spectrum Two FT-IR Spectrophotometer (Perkin-Elmer). Zeta potential was measured by a zeta sizer (Malvern). The fluorescence of DOX was detected by a fluorescence spectrophotometer 
(Perkin-Elmer). The in vivo drug distribution was measured by a small animals living imaging system (Maestro). In vivo ${ }^{1} \mathrm{H}-\mathrm{MRS}$ and $\mathrm{T} 1$ weight MRI were preferred on a 7.0 T magnetic resonance imaging equipment. In vivo CT imaging was carried out with an MIKASAHF 100HA CT instrument.

Synthesis of Ethanediamine- $\beta-C D$. $\beta-C D$ was synthesized according to our previous work. ${ }^{2}$ Briefly, $5 \mathrm{~g}$ of $\beta$-CD was dissolved in $150 \mathrm{~mL}$ of $0.4 \mathrm{M} \mathrm{NaOH}$ solution under a vigorous stirring. Then, $7.5 \mathrm{~g}$ of $p$ - $\mathrm{TsCl}$ was dissolved in the solution in an ice-bath. After a vigorous stirring for about $1 \mathrm{~h}$, the suspension was filtered. Then, $\mathrm{HCl}$ was added to the filtrate solution under a pH value of 5.0. The solution was kept at 4 ${ }^{\circ} \mathrm{C}$ overnight. The precipitate was washed with ethanol for three times. In order to remove unreacted $p-\mathrm{TsCl}$ and $\beta-\mathrm{CD}$, the crude product was recrystallized at $80^{\circ} \mathrm{C}$ for three times. After being dried at $50{ }^{\circ} \mathrm{C}$ under vacuum for $48 \mathrm{~h}, 2.5 \mathrm{~g}$ of OTs- $\beta$-CD was added into $15 \mathrm{~mL}$ of ethylenediamine. The reaction was kept at $80^{\circ} \mathrm{C}$ for $12 \mathrm{~h}$. The resultant solution was cooled to room temperature and then poured into ethanol. The precipitate was dissolved in water/methanol (3:1 v/v). Precipitation and dissolution procedures were repeated twice to wash the product sufficiently. Then, the product was dissolved in water and lyophilized for 3 days.

ESI-MS: Calculated: $1177[\mathrm{M}+\mathrm{H}]^{+}$, Found: 1177.

Synthesis of DA- $\beta$-CD. $200 \mathrm{mg}$ of EDA- $\beta-C D$ was dissolved in $10 \mathrm{~mL}$ of DMF. 176 $\mathrm{mg}$ of PyBOP, $208 \mathrm{mg}$ of diatrizoic acid and $40.5 \mathrm{mg}$ of HOBt were added into the above solution. $40 \mu \mathrm{L}$ of DIEA was dropwise added as a catalyst. The reaction was kept at $35{ }^{\circ} \mathrm{C}$ for $24 \mathrm{~h}$. Then the solution was precipitated with methanol. Precipitation and dissolution procedures were repeated twice to wash the product sufficiently. Finally, the product was dissolved in water and lyophilized for 3 days. 
White solid: ${ }^{1} \mathrm{H}-\mathrm{NMR}$ (Chemical shift, ppm; J, Hz) $1.82 \mathrm{ppm} \mathrm{CH}_{3}(6 \mathrm{H}, \mathrm{s}) ; 2.40-3.00$ ppm $\underline{\mathrm{CH}}_{2}-\mathrm{NH}-\underline{\mathrm{CH}}_{2} \underline{\mathrm{CH}}_{2}-\mathrm{NH}_{2}(6 \mathrm{H}, \mathrm{m}) ; 3.27-3.36$ ppm $\underline{\mathrm{CH}}_{2} \mathrm{OH}(12 \mathrm{H}, \mathrm{m}) ; 3.50-3.90$ ppm $\mathrm{CH}(14 \mathrm{H}, \mathrm{m}) ; 5.00$ ppm CH $(7 \mathrm{H}, \mathrm{s})$.

Synthesis of t-Bu-DOTA- $\beta$-CD. $14.9 \mathrm{mg}$ of $\mathrm{t}-\mathrm{Bu}$-DOTA was dissolved in $10 \mathrm{~mL}$ of DMF, and then $30.70 \mathrm{mg}$ of PyBOP, $15 \mu \mathrm{L}$ of DIEA and $5.13 \mathrm{mg}$ of HOBt were added sequentially in an ice bath. After the addition of $25 \mathrm{mg}$ of EDA- $\beta-C D$, the solution was stirred for $24 \mathrm{~h}$ at room temperature. The final product was precipitated with acetone. White solid: ${ }^{1} \mathrm{H}-\mathrm{NMR}: 1.13-1.37 \mathrm{ppm} \mathrm{CH}(27 \mathrm{H}, \mathrm{d}) ; 2.20-2.50 \mathrm{ppm} \mathrm{NH}-\underline{\mathrm{CH}} 2 \mathrm{CH} 2-\mathrm{NH}$ $(16 \mathrm{H}, \mathrm{m}) ; 3.16$ ppm N-$\underline{\mathrm{CH}}(6 \mathrm{H}, \mathrm{m}) ; 2.52-3.20 \mathrm{ppm} \underline{\mathrm{CH}_{2}}-\mathrm{NH}-\underline{\mathrm{CH}_{2}} \underline{\mathrm{CH}}_{2}-\mathrm{NH}_{2}(6 \mathrm{H}, \mathrm{m}) ;$ 3.32-3.40 ppm $\underline{\mathrm{CH}}_{2} \mathrm{OH}(12 \mathrm{H}, \mathrm{m}) ; 3.60-3.90$ ppm CH $(14 \mathrm{H}, \mathrm{m}) ; 5.04$ ppm CH $(7 \mathrm{H}, \mathrm{m})$. $10 \mathrm{mg}$ of product and $2.14 \mathrm{mg}$ of $\mathrm{GdCl}_{3} \cdot 6 \mathrm{H}_{2} \mathrm{O}$ were then dissolved in $100 \mu \mathrm{L}$ of PBS ( $\mathrm{pH}$ 6.0). After $24 \mathrm{~h}$ of stirring, the $\mathrm{pH}$ value was adjusted to 8.0 in order to remove the unreacted $\mathrm{Gd}^{3+}$. The filtrate was then precipitated in acetone. The product was precipitated and dissolved for three times, and then lyophilized for 3 days.

Synthesis of Fc-PEG-Bz-MSN. $1.0 \mathrm{~g}$ of CTAB and $280 \mathrm{mg}$ of $\mathrm{NaOH}$ were dissolved in $480 \mathrm{~mL}$ of $\mathrm{DI}$ water and heated to $80{ }^{\circ} \mathrm{C}$. Then $5.0 \mathrm{~g}$ of TEOS was added dropwise under a vigorous stirring for about $20 \mathrm{~min}$. The reaction mixture was stirred vigorously at $80{ }^{\circ} \mathrm{C}$ for $2 \mathrm{~h}$. The resulting product was centrifuged (10000 r/min, $\left.15 \mathrm{~min}\right)$, washed with DI water and methanol for three times and then dried under vacuum.

$200 \mathrm{mg}$ of MSN and $100 \mu \mathrm{L}$ of 3-chloropropyltriethoxysilane were dissolved in 40 $\mathrm{mL}$ of toluene and $1 \mathrm{~mL}$ of methanol. The mixture was refluxed for $24 \mathrm{~h}$. Then the product was centrifuged, washed with DI water and methanol for several times and lyophilized to obtain the white powder. After that, $40 \mathrm{mg}$ of 1H-benzimidazole-5-carboxylic acid and $100 \mathrm{mg}$ of $\mathrm{Cl}-\mathrm{MSN}$ were dispersed in $5 \mathrm{~mL}$ of DMF. $20 \mu \mathrm{L}$ of DIEA and $2 \mathrm{mg}$ of tetrabutylammonium iodide were added. The mixture was maintained at $80{ }^{\circ} \mathrm{C}$ for $24 \mathrm{~h}$. After that, the product was centrifuged and washed 
with methanol for several times, and then lyophilized to obtain Bz-MSN. After that, 80 $\mathrm{mg}$ of Bz-MSN, $90 \mathrm{mg}$ of $\mathrm{NH}_{2}$-PEG-NH $\mu \mathrm{L}$ of DIEA were added into DMF. After $24 \mathrm{~h}$ of stirring, nanoparticles were centrifuged and washed with DI water and methanol for several times. The product was lyophilized to obtain $\mathrm{NH}_{2}$-PEG-Bz-MSN. A mixture of $200 \mathrm{mg}$ of modified MSN, $80 \mathrm{~mL}$ of methanol and $5 \mathrm{~mL}$ of $\mathrm{HCl}(37.4 \%)$ were refluxed at $80{ }^{\circ} \mathrm{C}$ for $48 \mathrm{~h}$ to remove the CTAB. After that, $10 \mathrm{mg}$ of $\mathrm{NH}_{2}$-PEG-Bz-MSN, $10 \mathrm{mg}$ of ferrocenecarboxylic acid, 28 $\mathrm{mg}$ of PyBOP and $6 \mu \mathrm{L}$ of DIEA were mixed and the reaction was carried out at room temperature for $24 \mathrm{~h}$. Then the product was centrifuged and washed with water/methanol for several times. The product was lyophilized to obtain FC-PEG-Bz-MSN.

Finally, $200 \mathrm{mg}$ of Fc-PEG-Bz-MSN was added into a $\mathrm{H}_{2} \mathrm{O} /$ methanol (1/1 wt/wt), and then $5 \mathrm{mg}$ of DOX was added. The mixture was stirred for $24 \mathrm{~h}$ at room temperature. centrifuged and washed with DI water thrice to obtain DOX@ FC-PEG-Bz-MSN. $30 \mathrm{mg}$ of FA- $\beta-C D, 30 \mathrm{mg}$ of $D A-\beta-C D$ and $30 \mathrm{mg}$ of t-Bu-DOTA- $\beta$-CD were added into $10 \mathrm{~mL}$ of DI water and stirred for $2 \mathrm{~h} .10 \mathrm{mg}$ of $\mathrm{FeCl}_{3} \cdot 6 \mathrm{H}_{2} \mathrm{O}$ was added as an oxidant. After $1 \mathrm{~h}$ of stirring, the product was centrifuged and washed with DI water/methanol for several times, and then lyophilized to obtain DOX@HIMSN.

Cyclic Voltammetry Test. Electrochemical experiments were performed with a three-electrode setup using a platinum wire and a $\mathrm{KCl}$ saturated calomel electrode (SCE) as the counter and gold electrodes. Cyclic voltammograms were recorded without ohmic drop compensation at $25{ }^{\circ} \mathrm{C}$. HIMSN $(0.1 \mathrm{mg} / \mathrm{mL})$ in $10 \mathrm{~mL}$ of sodium phosphate buffer (10 mM, pH 7.4 and $\mathrm{pH} 6.0$ ) was used as the supporting electrolyte solution for electrochemical studies of HIMSN. GSH treated HIMSN was collected 
after the centrifugation to remove GSH and dispersed on the above solution for cyclic voltammetry test.

Cell Culture and In Vitro Cytotoxicity. The cytotoxicity of DOX@HIMSN was examined by a MTT assay. 4T1 cells were seeded into a 96-well plate with a cell density of $5.0 \times 10^{4}$ per well. Cells were incubated in $100 \mu \mathrm{L}$ of MEM containing $10 \%$ FBS for $24 \mathrm{~h}$ in an incubator $\left(37^{\circ} \mathrm{C}, 5 \% \mathrm{CO}_{2}\right)$. After that, $100 \mu \mathrm{L}$ of MEM containing various concentrations of DOX@HIMSN and a particular agent $\left(50 \mathrm{mM} \mathrm{NH}_{4} \mathrm{Cl}, 0.1\right.$ mM BSO, $0.1 \mathrm{mM}$ BSO, $50 \mathrm{mM} \mathrm{NH}_{4} \mathrm{Cl}$ and PBS, respectively) were added and incubated for $24 \mathrm{~h}$. After that, the medium was replaced with $200 \mu \mathrm{L}$ of fresh medium. $20 \mu \mathrm{L}$ of MTT (5 mg/mL in PBS buffer) solution was added in and further incubated at $37{ }^{\circ} \mathrm{C}$ for $4 \mathrm{~h}$. Subsequently, the medium was removed and $150 \mu \mathrm{L}$ of DMSO was added. The absorbance was measured at $570 \mathrm{~nm}$ using amicroplate reader (Bio-Rad, Model 550, USA). The relative cell viability was calculated by (OD 570sample /OD 570 control $) \times 100 \%$, where OD 570 control was obtained in the absence of DOX@HIMSN and OD 570sample was obtained in the presence of DOX@HIMSN. The data was averaged from 8 independent experiments.

Cellular Uptake. Confocal laser scanning microscopic (CLSM) was used to further study the cellular uptake of DOX@HIMSN in 4T1 cells. The cells were seeded in a 35 $\mathrm{mm}$ culture dish with a density of $1.0 \times 10^{5}$ and then incubated in $1 \mathrm{~mL}$ of DMEM containing $10 \% \mathrm{FBS}$ at $37{ }^{\circ} \mathrm{C}$ for $24 \mathrm{~h}$. After that, $1 \mathrm{~mL}$ of MEM containing $2 \mu \mathrm{g}$ of DOX@HIMSN and a particular agent (50 mM NH${ }_{4} \mathrm{Cl}, 0.1 \mathrm{mM}$ BSO, $0.1 \mathrm{mM}$ BSO, 50 $\mathrm{mM} \mathrm{NH}_{4} \mathrm{Cl}$ and PBS, respectively) were added. After co-incubation for $8 \mathrm{~h}$, the medium was removed and cells were washed for three times. After that, cells were observed with CLSM. (Nikon C1-si, TE2000, Japan).

Immune Response of DOX@HIMSN. Dendritic cells were generated from the bone marrow (BM) of 6 week female C57BL/6 mice. Briefly, the bone marrow was obtained 
by flushing the femur and tibia with RPMI-1640 medium (Gibico) containing 10\% FBS. After treating with red blood cell lysis solution (Beyond time), BM cells were cultured in the presence of recombinant granulocyte-macrophage colony-stimulating factor (rGM-CSF) $(10 \mathrm{ng} / \mathrm{ml})$ and recombinant interleukin (IL) 4 (IL-4) $(10 \mathrm{ng} / \mathrm{ml})$ to generate bone marrow-derived dendritic cells (BMDC). 4T1 cells $\left(5 \times 10^{4}\right)$ in $200 \mu \mathrm{L}$ MEM medium were pre-treated with PBS, free DOX (25 $\mu \mathrm{M})$, and DOX@HIMSN with $25 \mu \mathrm{M}$ of DOX for $16 \mathrm{~h}$, respectively. Tumor cells and supernatant was then collected for high mobility group box-1 content analysis. 4T1 cells (pre-treated with PBS, DOX, and DOX@HIMSN) or the cell supernatant were added in $10^{5}$ of DCs and co-incubated for $6 \mathrm{~h}$, and then the mixture was collected for RT-PCR analysis of FPR1, CD86, IL-12P40 and IL-6.

In order to study the initiation of anti-tumor immune response, 4T1 tumor bearing mice were received i.v. injection of DOX@HIMSN (with a DOX concentration of 5 $\mathrm{mg} / \mathrm{kg}), \mathrm{DOX}(5 \mathrm{mg} / \mathrm{kg})$ and PBS $(100 \mu \mathrm{L}) .2$ days after the injection, mice were sacrificed and tumor slices were used for caspase-3/CD86 immunofluorescence staining.

Tumor immunofluorescence staining of caspase-3/CD8, caspase-3/DOX and caspase-3/granzyme-B fluorescents were used to investigate the cytotoxicity based cell killing and immunologic cell killing abilities of HIMSN. Mice were injected with 4T1 cells. Once tumors reached an approximate size of $100 \mathrm{~mm}^{3}$, mice were randomly divided into 4 groups with 7 mice each group. Mice were received i.v. injection of DOX@HIMSN (with a DOX concentration of $5 \mathrm{mg} / \mathrm{kg}$ ), DOX (5 mg/kg) and PBS (100 $\mu \mathrm{L})$ at 5 th and 20th days. The mice were sacrificed at the 25th day.

In vivo Blood Clearance Study. Tumor free female Balb/c mice were randomly divided into three groups. Then, DOX and DOX@HIMSN were intravenously injected through through the tail vain (at a DOX dose of $5 \mathrm{mg} / \mathrm{kg}$ ). $10 \mu \mathrm{L}$ of blood samples were 
collected through the tail vain at different time points $(0,10 \mathrm{~min}, 30 \mathrm{~min}, 1 \mathrm{~h}, 2 \mathrm{~h}, 4 \mathrm{~h}$, and $8 \mathrm{~h}$ ). The plasma was stored at $-80{ }^{\circ} \mathrm{C}$ for further analysis. Briefly, $10 \mu \mathrm{L}$ of plasma sample was mixed with $500 \mu \mathrm{L}$ of chloroform. The concentration of DOX was measured with a fluorescence spectrometer.

In Vivo Bio-distribution Study. When the subcutaneous tumor reached about $3 \mathrm{~mm}$ in diameter, in vivo fluorescence imaging was performed using a Maestro imaging system (CRi, Inc, Woburn, MA). In order to deplete the intracellular GSH and decrease the acidic $\mathrm{pH}$, BSO $(2.25 \mathrm{mmol} / \mathrm{kg})$ and $\mathrm{NaHCO}_{3}$ were intratumoral injected into mice, respectively. For the drug distribution study, DOX@HIMSN was i.v. injected at a dose of $5 \mathrm{mg} / \mathrm{kg}, 24$ hours before the in vivo imaging. Each mouse was sacrificed. Heart, liver, spleen, lung, kidney and tumor were taken out. A set of filters specifically for DOX imaging (excitation, $488 \mathrm{~nm}$; emission, $580 \mathrm{~nm}$ ) was applied. Then, a serious of organs were collected for frozen section examination. The distribution within the organization was imaged by CLSM.

In vivo Anti-tumor Therapy. All animal experiments were performed according to guidelines for laboratory animals established by the Wuhan University Center for Animal Experiment/A3-Lab. Mice were injected with 4T1 cells. Once tumors reached an approximate size of $100 \mathrm{~mm}^{3}$, mice were randomly divided into 4 groups with 7 mice each group. Then, mice were received i.v. injection of DOX@HIMSN (with a DOX concentration of $5 \mathrm{mg} / \mathrm{kg})$, DOX ( $5 \mathrm{mg} / \mathrm{kg}$ ) and PBS for $100 \mu \mathrm{L}$ a day at $5^{\text {th }}$ and 20th days. Tumor size and mice weight were measured immediately before the injection. Tumor volume was defined as: $V=W^{2} \times L / 2$, where $W$ and $L$ were the shortest and longest diameters of tumors, respectively. Relative tumor volume was defined as $V / V_{0}\left(V_{0}\right.$ was the tumor volume when the treatment was initiated). After mice were sacrificed, H\&E staining, immunofluorescence staining and immunohistochemical staining were carried out. In order to examine lung metastasis, 
mice sacrificed and India ink (15\%) was injected through the trachea to their lungs. Then, the lungs were collected and fixed in a $4 \%$ paraformaldehyde solution for 2 days and then photographed and white spots on the lungs (tumor metastasis) were counted. Livers were collected and photographed immediately, and white spots on the lungs (tumor metastasis) were counted. The in vivo therapy via s.c. injection was also performed on 4T1 tumor bearing Balb/c mice. Once tumors reached an approximate size of $100 \mathrm{~mm}^{3}$, mice were randomly divided into 3 groups with 5 mice each group. Then, mice were injected with DOX@HIMSN (with a DOX concentration of $5 \mathrm{mg} / \mathrm{kg}$ ), DOX (5 mg/kg) and PBS for $100 \mu \mathrm{L}$ a day for 10 days. After mice were sacrificed, H\&E staining was used for further histological examinations.

Western Blot and Immunofluorescence Staining. In the 25th day of the treatment, mice of various groups treated by PBS, DOX, DOX@HIMSN and DOX@IMSN were sacrificed. Tumors, lungs, livers, spleens and blood serum were lysed and collected. Then, lysate was treated with $50 \mu \mathrm{L}$ of RIPA buffer and resuspended in $50 \mu \mathrm{L}$ of SDS buffer with $1 \% \beta$-mercaptoethanol. Then the samples were heated for $5 \mathrm{~min}$ and separated on a 10\% SDS-PAGE (15 $\mu \mathrm{L}$ per lane). After electrophoresis, proteins were transfered to a PVDF membrane (Millipore). The PVDF membranes were then blocked in PBS with 5\% skim milk for $1 \mathrm{~h}$. Cleaved IL-12 (Bioss), IL-1 1 (Proteintech Group, Inc), IFN-y (Abcam), TNF-a (Santa), CD4 (Proteintech Group, Inc), CD8 (Proteintech Group, Inc), CD19 (Proteintech Group, Inc) and CD86 (Proteintech Group, Inc) were detected. The membranes with the primary antibody rabbit anti-mice antibody (1:2000 dilution) overnight at $4{ }^{\circ} \mathrm{C}$ and then with the secondary antibody HRP labeled goat antirabbit IgG (1:3000 dilution, KPL) for $1 \mathrm{~h}$. Specific proteins were monitored by enhanced chemiluminescence. GADPH (Abcam, Rabbit) was employed as protein loading control. 
Tumor samples were collected, rinsed with cold PBS and immediately frozen at $-80{ }^{\circ} \mathrm{C}$. Tissue slices were prepared by means of a frozen section machine. After blocking non-specific binding of antibody with 10\% fetal calf serum (FCS) (1 h), samples were stained with primary antibodies specific for CD86, cleaved caspase-3 (Biovision Corp), CD8 and CD4 in a humidified chamber (2 h). After the samples were washes with 10\% FCS for 3 times, FITC or Cy-5.5 conjugated appropriate secondary antibodies (Molecular Probes-Life Technologies Inc) $(5 \mu \mathrm{g} / \mathrm{ml}$ ) were added. Nuclei were stained with $10 \mu \mathrm{M}$ DAPI. Coverslides were mounted with Fluoromount-GTM medium (Southern Biotechnologies). Slices are imaged with an LSM 710 Confocal Microscope (Zeiss, Jena, Germany). Quantitative study of immunofluorescence staining and fluorescent colocalization analysis were performed with Image $\mathrm{J}$.

\section{Dead-cell proximity index, Euclidean distance matrix analysis and Fluorescence}

Colocalization Analysis. The measurement of dead-cell proximity index was according to the literature. ${ }^{1}$ Briefly, the dead-cell proximity index is the ratio between the distance of $\mathrm{CD} 86^{+} \mathrm{DCs}$ from caspase- $3^{+}$cancer cells and the distance of $\mathrm{CD} 86^{+}$ DCs from caspase- $3^{-}$cancer cells. Here, Image J was used to measure the distance of $\mathrm{CD} 86^{+} \mathrm{DCs}$ from caspase $-3^{+}$cancer cells and the distance of $\mathrm{CD} 86^{+} \mathrm{DCs}$ from caspase- $3^{-}$cancer cells. Dead-cell proximity index in 15 images was measured and the result was presented in both box plot and histogram.

Euclidean distance matrix analysis was used to compare the dissimilarity between CD86 fluorescence and caspase-3 fluorescence distribution. The measurement of euclidean distance matrix analysis is according to the literature report. ${ }^{2}$ Briefly, red channel and green channel of RGB images were translated into matrices by using Matlab software. Then, matrices were normalized and the equation 1 was used to calculate the mean distance between CD86 fluorescence and caspase-3 fluorescence. 
Here, $d$ is the Euclidean distance, $f_{r}$ is the fluorescence intensity of red channel and $f_{g}$ is the fluorescence intensity of the green channel. For Euclidean distance matrix analysis, 15 images were measured in each group and the result was presented in both box plot and histogram.

In order to study the fluorescence colocalization in the immunofluorescence section, Pearson's coefficients and Mander overlap coefficient between green channel and red channel were calculated with the help of "Colocalization Finder" plugin for Image J (http://rsb.info.nih.gov/ij/plugins/colocalization-finder.html). ${ }^{3}$

In Vitro Real-time PCR Aassay. In order to quantify the intracellular transcription level of FPR-1, DC-86, IL-6 and IL-12 genes, RNA of DCs was extracted. The RNA samples were reverse-transcribed to cDNA using a first stand cDNA synthesis kit (TOYOBO, Japen). The relative expression of FPR-1 and IL-1 $\beta$ was then measured via real-time PCR using a StepOne ${ }^{\mathrm{TM}}$ Real-Time PCR (Life technologies, USA). Specific primers for the genes were provided by Invitrogen. Each PCR reaction was performed in $10 \mu \mathrm{L}$ of a reaction mixture containing $5.0 \mu \mathrm{L}$ of $2 \times$ qPCR Mix, $1.0 \mu \mathrm{L}$ of each primer, $1.0 \mu \mathrm{L}$ of template, $2.8 \mu \mathrm{L}$ of $\mathrm{DI}$ water and $0.2 \mu \mathrm{L}$ of rox. The samples were then subjected to cycling conditions as the protocol specified in the SYBR® Premix Ex Taq gene expression assay kit. The level of gene expression, normalized to GAPDH, was then calculated using the $\triangle \triangle C T$ formula.

MR Imaging. The suspension of HIMSN with various gadolinium concentrations were diluted by DI water ultrasonically to obtain a final gadolinium concentration in the range of 0.1 to $0.0625 \mathrm{mM}$. Samples were transferred to NMR tubes, placed in a 7.0 MR scanner, and tested using various sequences. The T1 relaxation time of the suspension was computed using Paravision 5.0. The T1 relaxation rate (1/T1) was 
plotted versus the gadolinium concentrations and the $\mathrm{T} 1$ relaxivity was determined based on a linear fit. The in vivo MR imaging was performed on Balb/c mice weighting approximately $15 \mathrm{~g}$. Mice were anaesthetized by isoflurane before DOX@HIMSN were administered via i.v. injection. Then, mice were scanned before and after the administration of $0.1 \mathrm{~mL}$ suspension of DOX@HIMSN at a Gd dose of $0.5 \mathrm{mg} / \mathrm{kg}$ body weight. The T1-weighted MR images of the tumor were obtained on a MR scanner.

CT Imaging. Male Balb/c nude mice weighing about $15 \mathrm{~g}$ were used as an animal model. In vivo X-ray/CT imaging were performed with an MIKASAHF 100HA CT instrument. After mice were anesthetized (with $100 \mu \mathrm{L} 10 \%$ chloral hydrate), $100 \mu \mathrm{L}$ of the DOX@HIMSN (1 mg/mL) solution were tail vain injected into mice. All CT scans were performed using the above CT system.

In Vivo ${ }^{1} \mathrm{H}$-MR Spectra Analysis. ${ }^{1} \mathrm{H}$-magnetic resonance spectra $\left({ }^{1} \mathrm{H}-\mathrm{MRS}\right)$ were recorded in a 7.0 T magnetic resonance spectroscopy facility with a Bruker BioSpec 70/20USR spectrometer (Bruker SADIS, Wissembourg, France) operating at 300 $\mathrm{MHz}$, and equipped with a Paravision 5.0 operating system. Fully relaxed one dimensional spectra with $90^{\circ}$ pulses $(10 \mathrm{~ms})$ were recorded at $25^{\circ} \mathrm{C}$. The strong water peak at $4.80 \mathrm{ppm}$ was inhibited. The heat map analysis and cluster analysis were performed with the Heml 1.0.

Comprehensive Assessment of DOX and DOX@HIMSN treatment. Considering the distinction of the possible range of each subscale score. Different aspects were converted into centesimal scores to compare these values with each other. Tumor inhibition rate, metastasis inhibition rate, immune response rate and immune response suppression rate were determined using the following formula: $\mathrm{N}=\left(\mathrm{N}_{C}-\mathrm{N}_{\mathrm{M}}\right) / \mathrm{N}_{C} \times 100 \%$, where $\mathrm{N}_{C}$ can be the tumor weight, nodule number, Euclidean distance matrix analysis or WBC count of PBS group and $\mathrm{N}_{\mathrm{M}}$ is the tumor weight, nodule number, Euclidean distance matrix analysis or WBC count of DOX or 
DOX@HIMSN group. Tumor targeting score was defined as $N=\mathrm{F}_{\top} / \mathrm{F}_{\mathrm{A}} \times 100 \%$, where $F_{T}$ is the fluorescence intensity of tumor and $F_{A}$ is the fluorescence intensity of all organs.

Statistical Analysis. Statistical analysis was performed using a Student's t-test. The differences were considered to be statistical significant for $p$ value $<0.05$. For all the animals study, $\mathrm{n}>3$.

\section{Analysis of Experimental Results}

FT-IR analysis of various nanoparticles. The FT-IR analysis of various nanoparticles was shown in Figure S3. In the FT-IR spectra, all samples showed the absorption of the Si-O-Si bond at around $1086 \mathrm{~cm}^{-1}$ and silanol bending vibration near $810 \mathrm{~cm}^{-1}$. For CTAB@MSN, peaks around $2900 \mathrm{~cm}^{-1}$ were contributed to methyl and methylene tretching vibrations of $\mathrm{CTAB}$. Since the $\mathrm{C}-\mathrm{Cl}$ bond has a very weak signal, no significant changes occurred in FT-IR spectrum of Cl-MSN. However, after the modification of benzimidazole, a peak at $1445 \mathrm{~cm}^{-1}$ could be observed clearly, which was due to the benzene structure of the benzimidazole. For Bz-MSN, enhanced peaks around $1400 \mathrm{~cm}^{-1}$ were attributed to ring vibrations. Peaks around $1620 \mathrm{~cm}^{-1}$ may be assigned to $\mathrm{C}=\mathrm{N}$ stretching. After the pegylation of Bz-MSN, peaks near 2920 $\mathrm{cm}^{-1}$ were assigned to methylene stretching vibrations of PEG. For Fc-PEG-Bz-MSN, its C-C stretching vibration was at around $1106 \mathrm{~cm}^{-1}$. Besides, in the cyclic voltammetry test, a strong peak at $0.3 \mathrm{mV}$ of Fc-PEG-Bz-MSN indicated the successful modification of Fc. After the DOX loading process, remarkably increased peaks around $1500 \mathrm{~cm}^{-1}$ were due to the ring vibration of DOX. The increase of the signal at around $3300 \mathrm{~cm}^{-1}$ was attributed to hydroxy groups in $\beta-C D$.

Zeta potential analysis of various nanoparticles. Zeta potential analysis of various nanoparticles was presented in Table S1. CTAB@MSN showed a negative 
zeta-potential of about $-3.77 \mathrm{mV}$. However, after the removal of the cationic surfactant CTAB, zeta potential was changed to $-21.7 \mathrm{mV}$. After the chlorination of the MSN, zeta potential was $-18 \mathrm{mV}$ because of the decrease surface Si-OH group. Bz-MSN showed a zeta potential of $2.1 \mathrm{mV}$, which may come from the presence of abundant amount of imidazole ring. For $\mathrm{NH}_{2}-\mathrm{PEG}-\mathrm{Bz}-\mathrm{MSN}$, the zeta potential reached $17 \mathrm{mV}$. However, the zeta potential of Fc-PEG-Bz-MSN was reversed to $-22.1 \mathrm{mV}$. After the host-guest combination of nanoparticles with $\beta-C D$, the zeta potential in DI water was $-37 \mathrm{mV}$, which may come from the presence of abundant hydroxy in $\beta-C D$.

In vivo cytokines analysis after treatment with various nanoparticles. In order to study the in vivo immune response of DOX@MFMSN, particular soluble cytokines secreted from DCs were evaluated. As we known, IL-12 and interleukin-1 $\beta$ (IL-1 $\beta$ ) were able to recruit strong therapeutic T cells immunity for tumor-suppression. Besides, interferon gamma (IFN- $\gamma$ ) and tumor necrosis factor alpha (TNF- $\alpha$ ) were classical cytokines of cellular immunity, which played an important role in the anti-tumor immune response. ${ }^{4}$ Thus, the secretion of IL-12, IL-1 $\beta$, IFN- $\gamma$ and TNF- $\alpha$, together with the markers (CD4, CD8) of T cells and matural DCs (CD86) in the spleen, tumor and serum after various treatments were analyzed. As shown in Figure 5 , the secretion of IL-12, IL-1 $\beta$, IFN- $\gamma$ and TNF- $\alpha$ in various organs were enhanced after treatment by DOX@HIMSN, as compared with DOX@IMSN, free DOX and PBS groups. Additionally, the DOX@HIMSN treatment resulted in increased CD86, CD4 and CD8 levels in lymphocytes, which indicated that a rapid immune response was initiated. ${ }^{5}$ These macroscopical indexes suggested that DOX@HIMSN could initiate a favorable anti-tumor immune response. 
Table S1. Zeta Potential of functional nanoparticles.

\begin{tabular}{cc}
\hline Sample & Zeta Potential $(\mathrm{mV})$ \\
\hline CTAB@MSN & -3.7 \\
MSN & -21.7 \\
CI-MSN & -18.0 \\
Bz-MSN & 2.1 \\
$\mathrm{NH}_{2}$-PEG-Bz-MSN & 17.0 \\
FC-PEG-Bz-MSN & -22.1 \\
HIMSN & -37.0 \\
\hline
\end{tabular}


Table S2. Peak assignment of ${ }^{1} \mathrm{H}$-MRS.

\begin{tabular}{|c|c|c|c|}
\hline $\begin{array}{l}\text { Chemical Shift } \\
\qquad(\mathrm{ppm})\end{array}$ & Metabolin & $\begin{array}{c}\text { Chemical Shift } \\
(\mathrm{ppm})\end{array}$ & Metabolin \\
\hline $1.0-1.5$ & Fatty Acyl & $3.10-3.18$ & Spermine \\
\hline 1.34 & Lactate & $3.20-3.22$ & PC,choline \\
\hline 1.82 & Spermine & 3.24.3.45 & $\begin{array}{c}\text { Taurine, } \\
\text { glutathione }\end{array}$ \\
\hline $2.00-2.20$ & $\begin{array}{l}\text { Glutamate, } \\
\text { Glutamine, } \\
\text { glutathione }\end{array}$ & $3.50-3.62$ & Choline, $\mathrm{PC}$ \\
\hline 2.17 & Glutathione & $3.70-3.85$ & $\begin{array}{l}\text { Glutamate, } \\
\text { Glutamine, } \\
\text { glutathione }\end{array}$ \\
\hline $2.35-2.45$ & Glutamate & 4.12 & Lactate \\
\hline $2.68-2.79$ & Aspartate & 4.20 & PC \\
\hline 2.98 & Glutathione & 4.65 & a-Glucose \\
\hline 3.04 & Creatine & 5.20 & b-Glucose \\
\hline
\end{tabular}


Table S3. Primer sequence for RT-PCR assay.

\begin{tabular}{|c|c|c|c|}
\hline \multicolumn{2}{|c|}{ Gene } & Sequence & Length(bp) \\
\hline \multirow{2}{*}{ GAPDH } & Forward & 5`-TGAAGGGTGGAGCCAAAAG-3` & \multirow{2}{*}{227} \\
\hline & reverse & 5`-AGTCTTCTGGGTGGCAGTGAT-3` & \\
\hline \multirow{2}{*}{ FPR-1 } & Forward & 5`-ATTCGTTTGACCACAGTCCCT-3` & \multirow{2}{*}{159} \\
\hline & reverse & 5'-GCTGAACCCAATGATGAACCT-3` & \\
\hline \multirow{2}{*}{ M-IL-6 } & Forward & $5^{`}$-GCAATGGCAATTCTGATTGTATG-3` & \multirow{2}{*}{172} \\
\hline & reverse & 5`AAGGACTCTGGCTTTGTCTTTCT-3` & \\
\hline \multirow{2}{*}{$\begin{array}{c}\text { M-CD8 } \\
6\end{array}$} & Forward & $5 `$ CTAAGCAAGGTCACCCGAAAC-3` & \multirow{2}{*}{284} \\
\hline & reverse & 5`- GGCCACAGTAACTGAAGCTGTAAT-3` & \\
\hline \multirow{2}{*}{$\begin{array}{c}\text { IL-12P4 } \\
0\end{array}$} & Forward & 5` CATCAGGGACATCATCAAACCA-3` & \multirow{2}{*}{205} \\
\hline & reverse & 5`-GAACGCACCTTTCTGGTTACAC-3` & \\
\hline
\end{tabular}



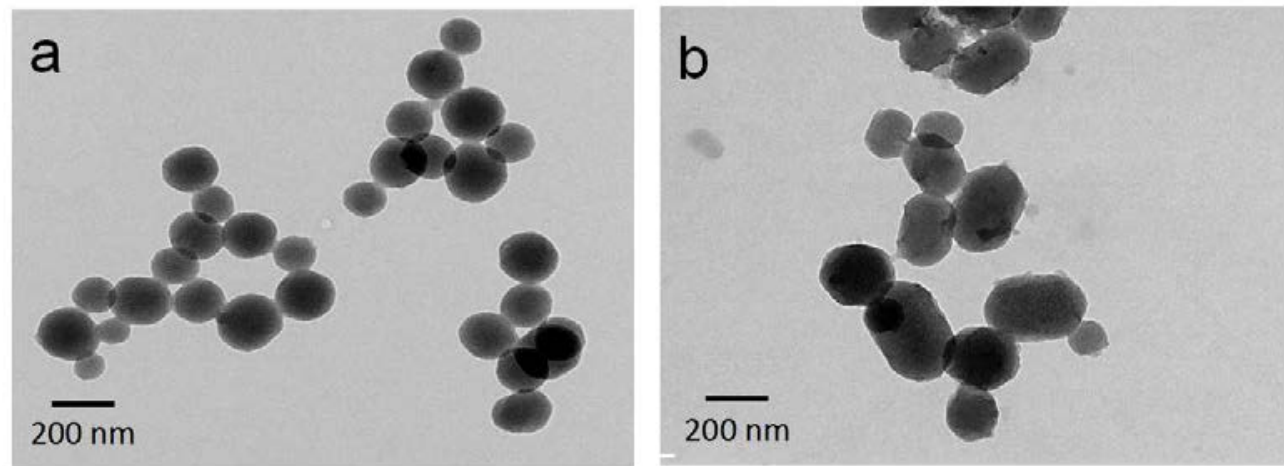

Figure S1. TEM imaging of (a) MSN and (b)HIMSN. 


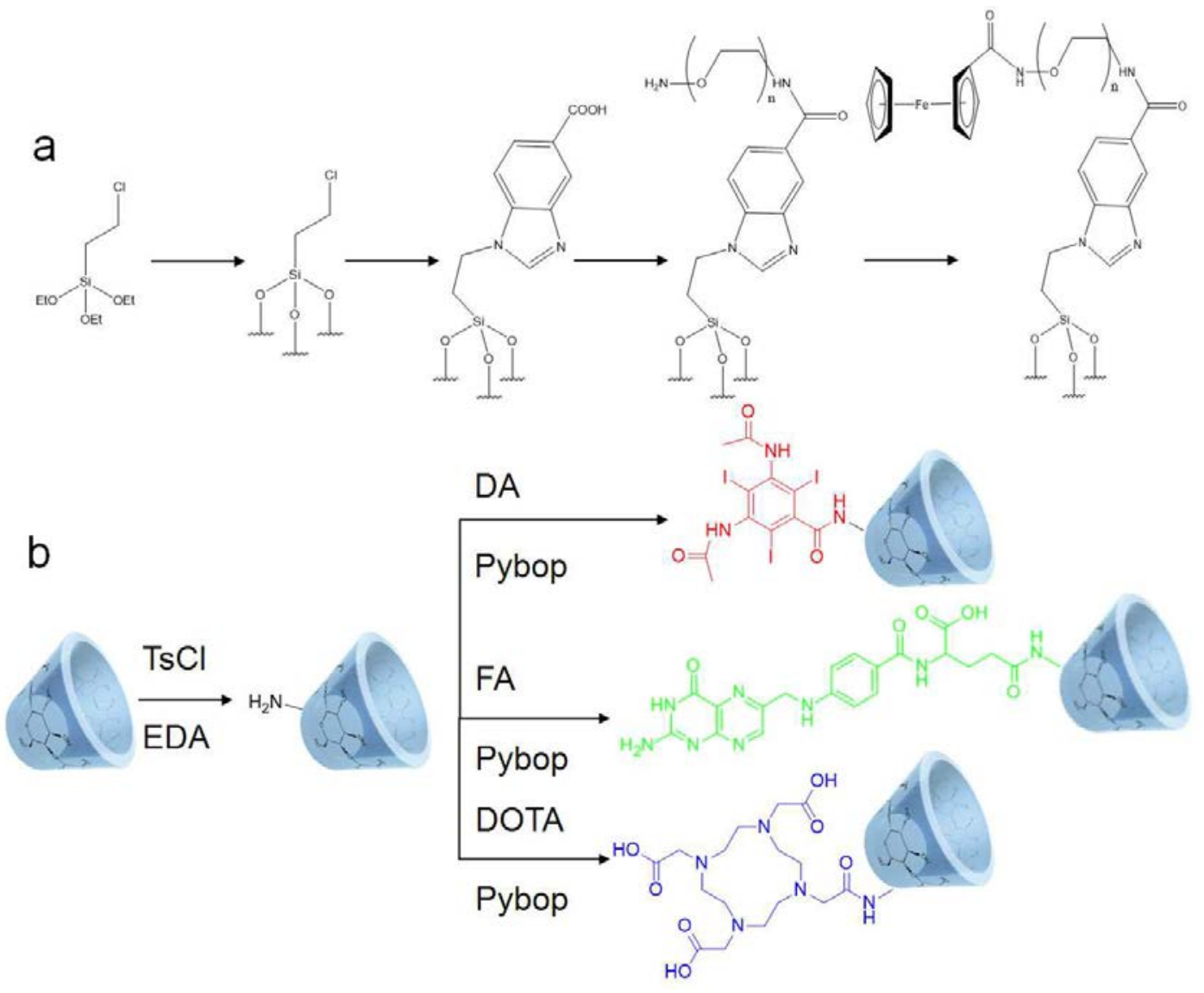

Figure S2. Synthesis of (a) FC-PEG-Bz-MSN; (b) FA- $\beta-C D$, DA- $\beta-C D$ and DOTA- $\beta-C D$ 


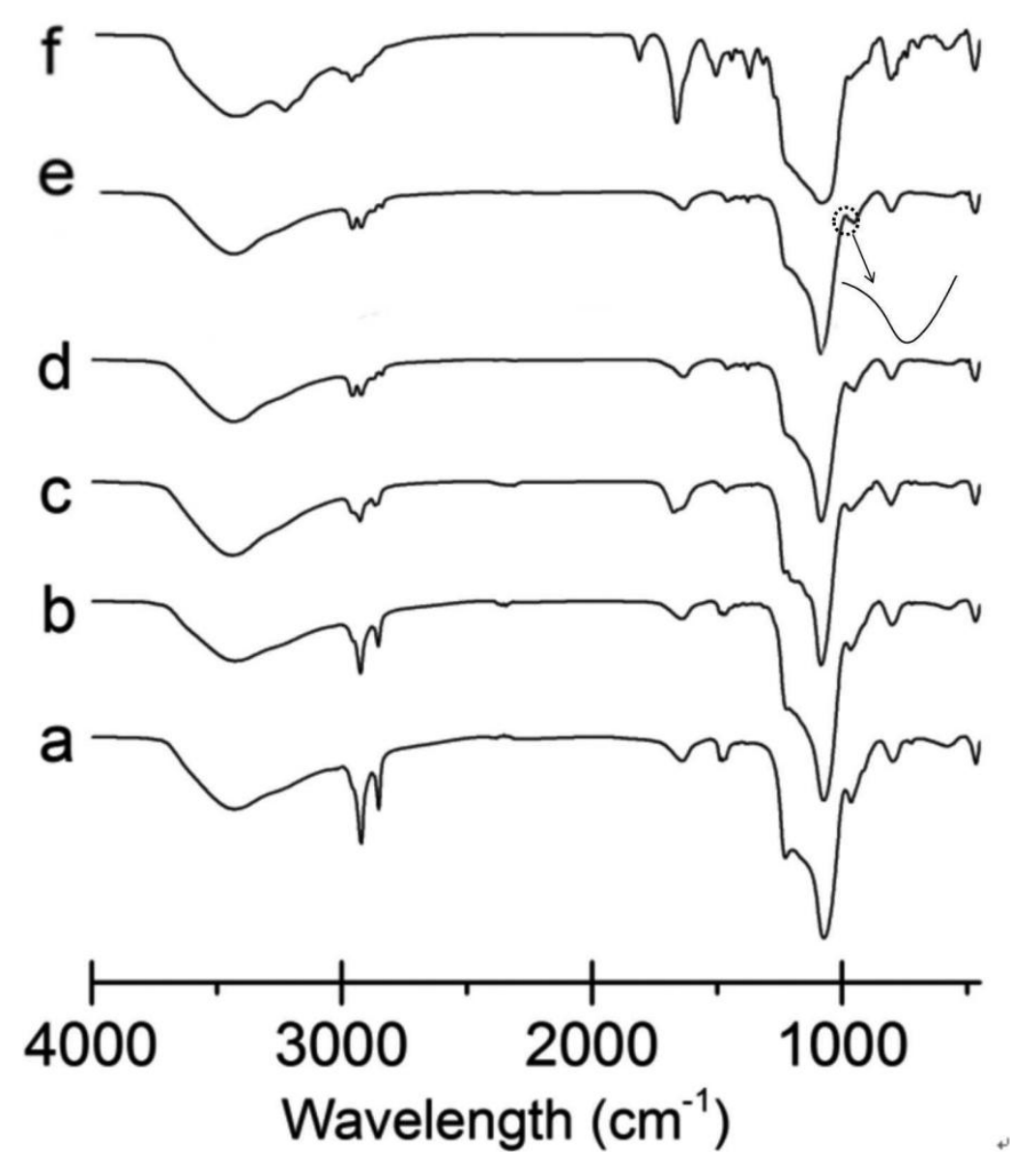

Figure S3. FT-IR spectra of (a) CTAB@MSN; (b) Cl-MSN; (c) Bz-MSN; (d) $\mathrm{NH}_{2}$-PEG-Bz-MSN; (e) Fc-PEG-Bz-MSN; and (f) DOX@HIMSN. 


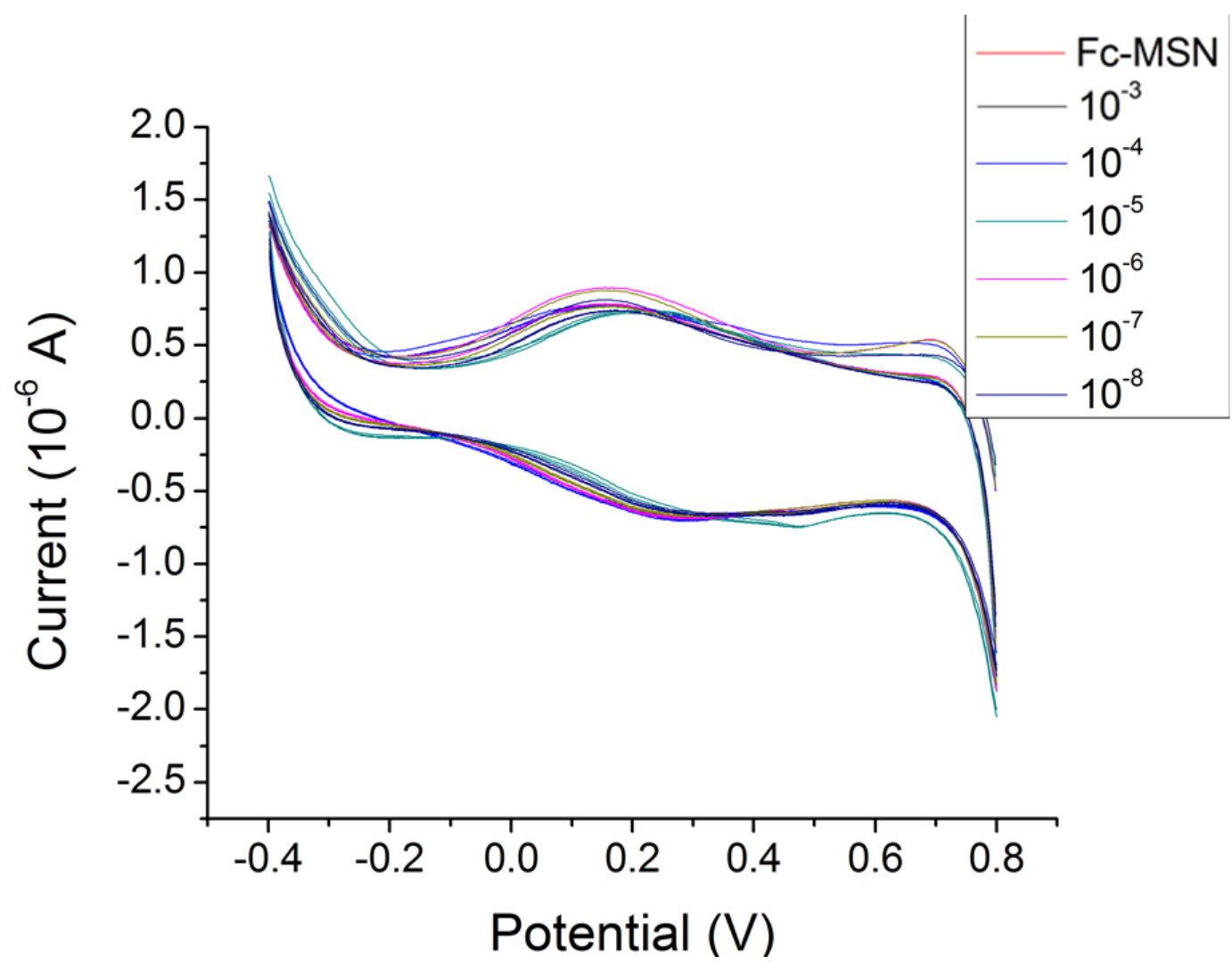

Figure S4. Cyclic voltammetry of HIMSN to measure the grafting ratio of Fc-PEG-Bz. 

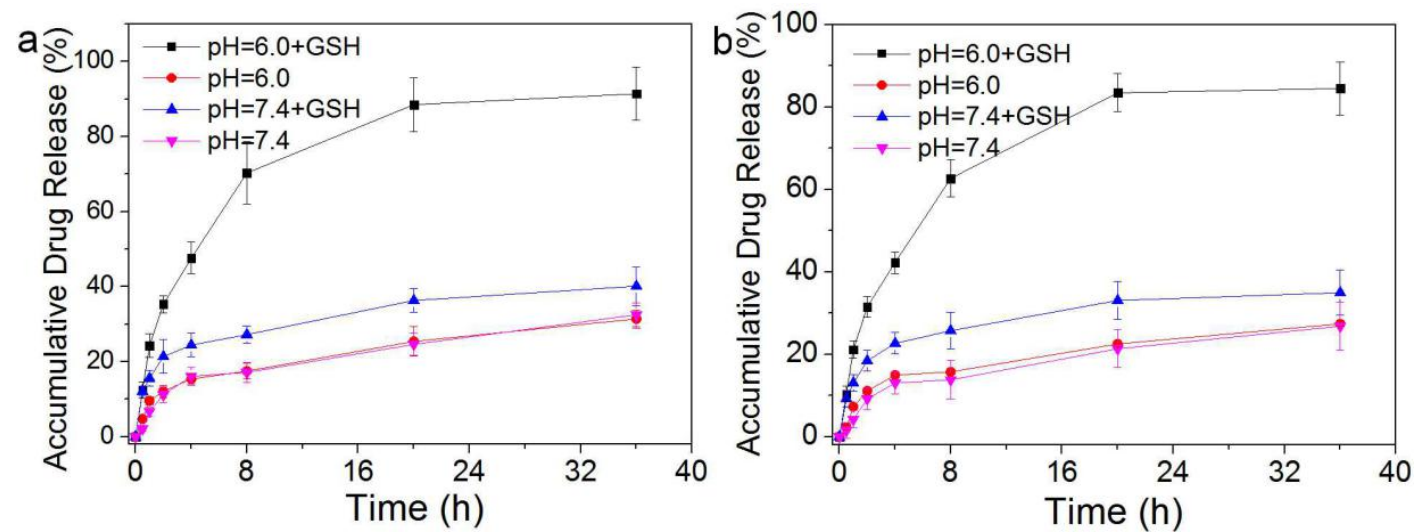

Figure S5. Drug release profile of (a) DOX@HIMSN and (b) DOX@IMSN at various conditions. 


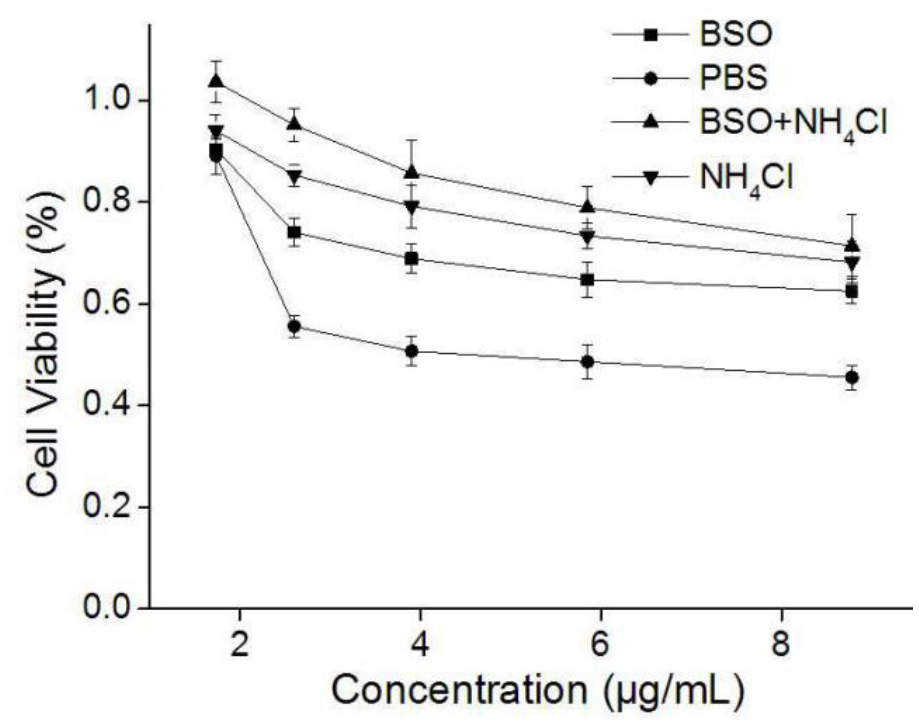

Figure S6. In vitro cell viability assay of $4 \mathrm{~T} 1$ cells after $8 \mathrm{~h}$ of co- incubation with DOX@HIMSN with GSH depletion and restoration of intracellular pH . 


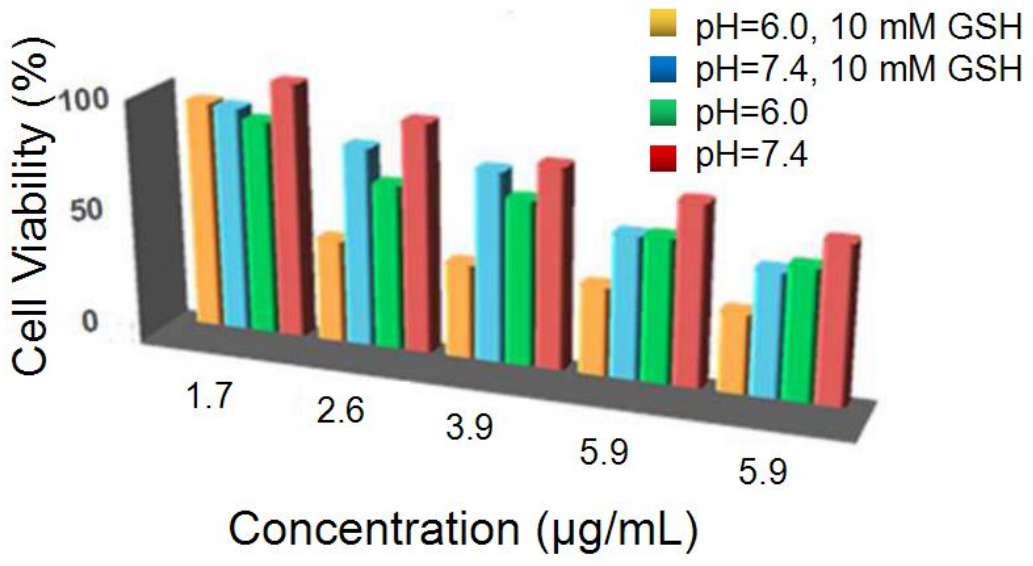

Figure S7. In vitro cell viability assay of SCC-7 cells co-incubated with DOX@HIMSNs at pH 6.0 with $10 \mathrm{mM}$ of GSH, pH 7.4 with $10 \mathrm{mM}$ of GSH, pH 6.0 and $\mathrm{pH} 7.4$ respectively. 


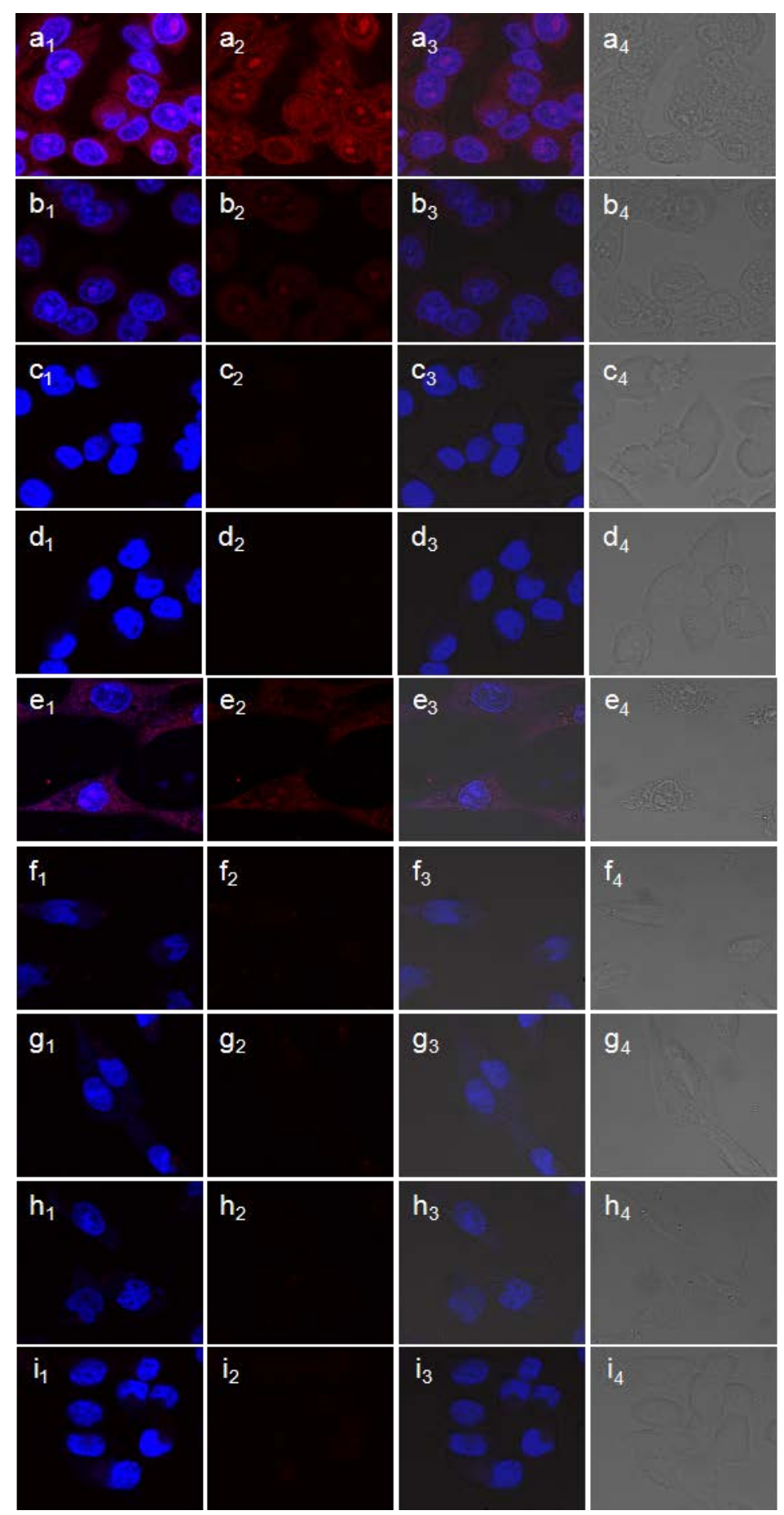

Figure S8. Confocal laser scanning microscopy (CLSM) images of KB cells (a-d) and Cos-7 cells (e-h) co-incubated with DOX@HIMSN at PBS, BSO, $\mathrm{NH}_{4} \mathrm{Cl}$ and BSO/ $\mathrm{NH}_{4} \mathrm{Cl}$, respectively; (i) KB cells co-incubated with DOX@HIMSN after 2 h of free FA treatment. Image 1: Red and blue field; image 2: red fluorescence field; image 3: overlapped field; image 4: Bright field. 

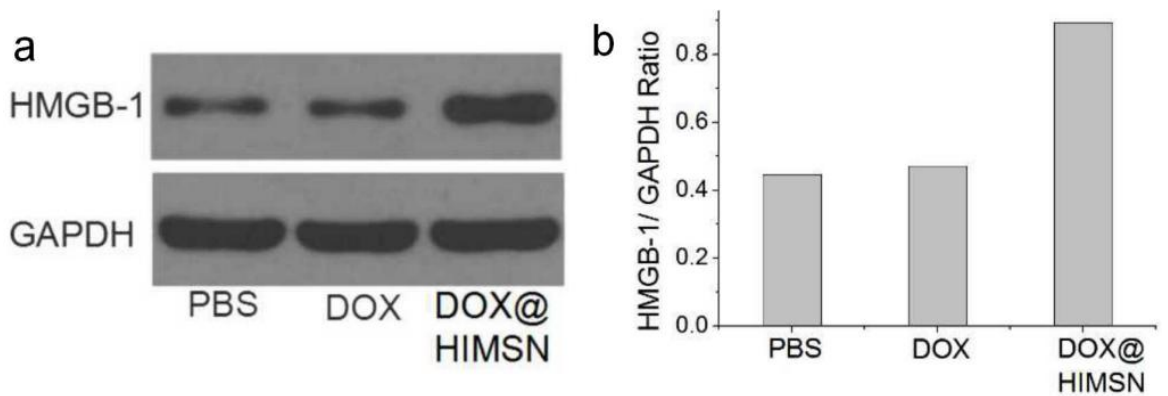

Figure S9. (a) Qualitative and (b) quantitative western blot analysis of high mobility group box-1 in 4T1 cells after the co-incubation with DOX and DOX@HIMSN. (HMGB-1: High mobility group box-1) 


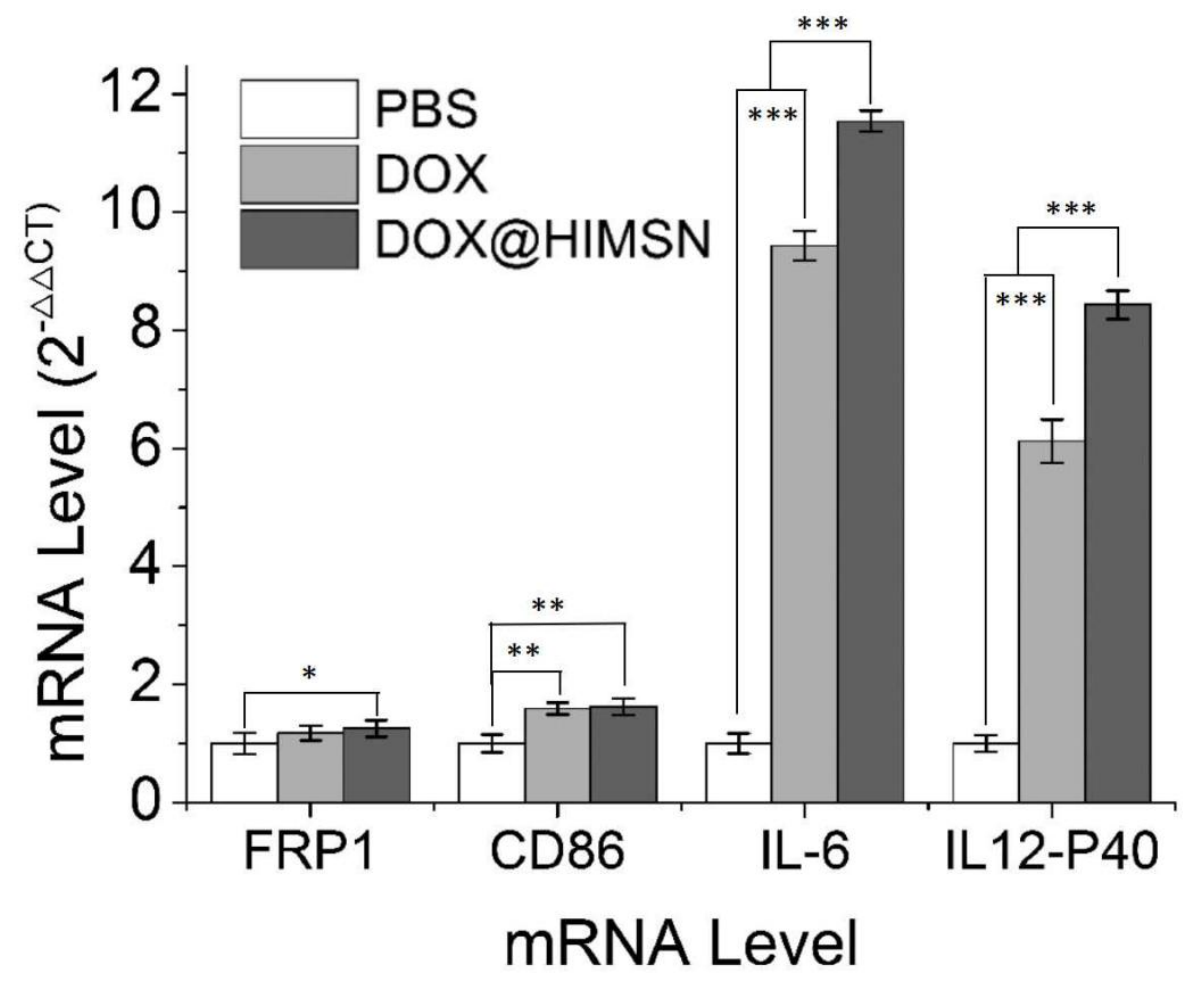

Figure S10. RT-PCR analysis of FPR1, CD86, IL-6 and IL12-P40 of DCs after coincubation with DOX or DOX@HIMSN treated 4T1 cells. $\left({ }^{\star} p<0.05,{ }^{\star \star} p<0.01,{ }^{\star \star \star} p<\right.$ $0.001)$ 


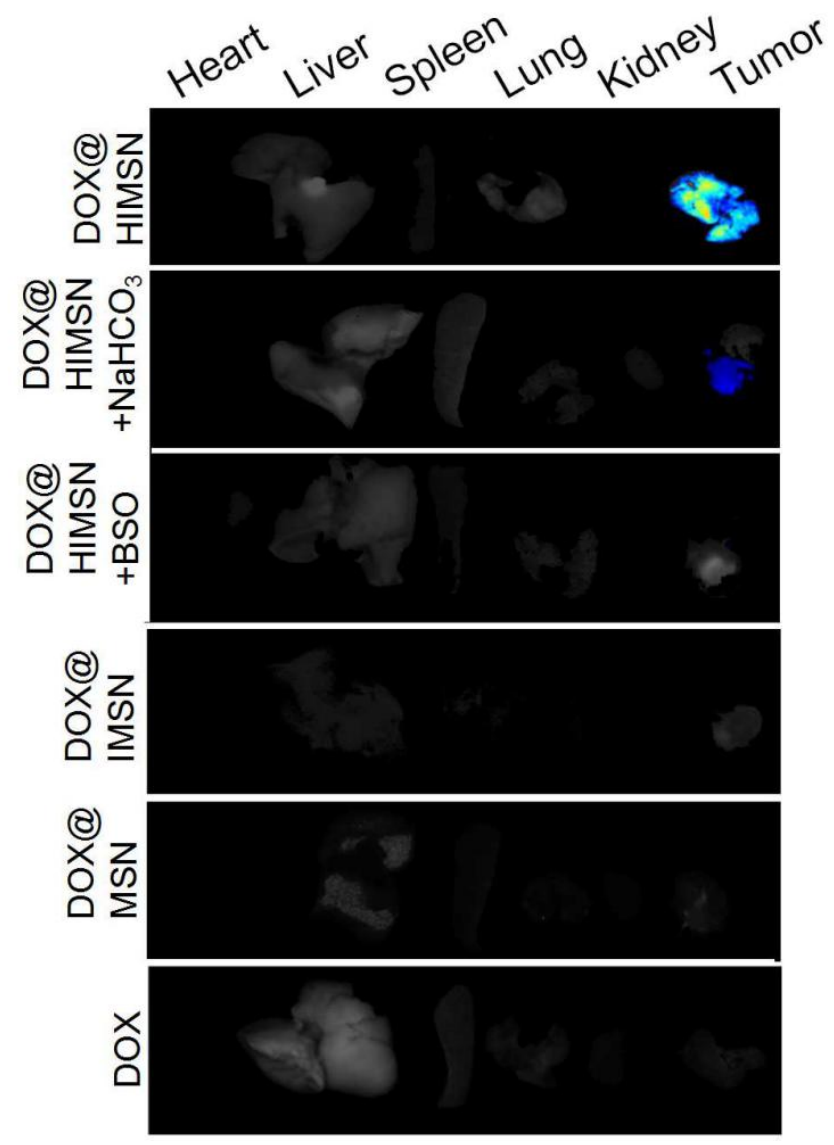

Figure S11. Ex vivo fluorescence imaging for heart, lung, liver, spleen, tumor and kidney $24 \mathrm{~h}$ after the i.v. injection of various agents. 

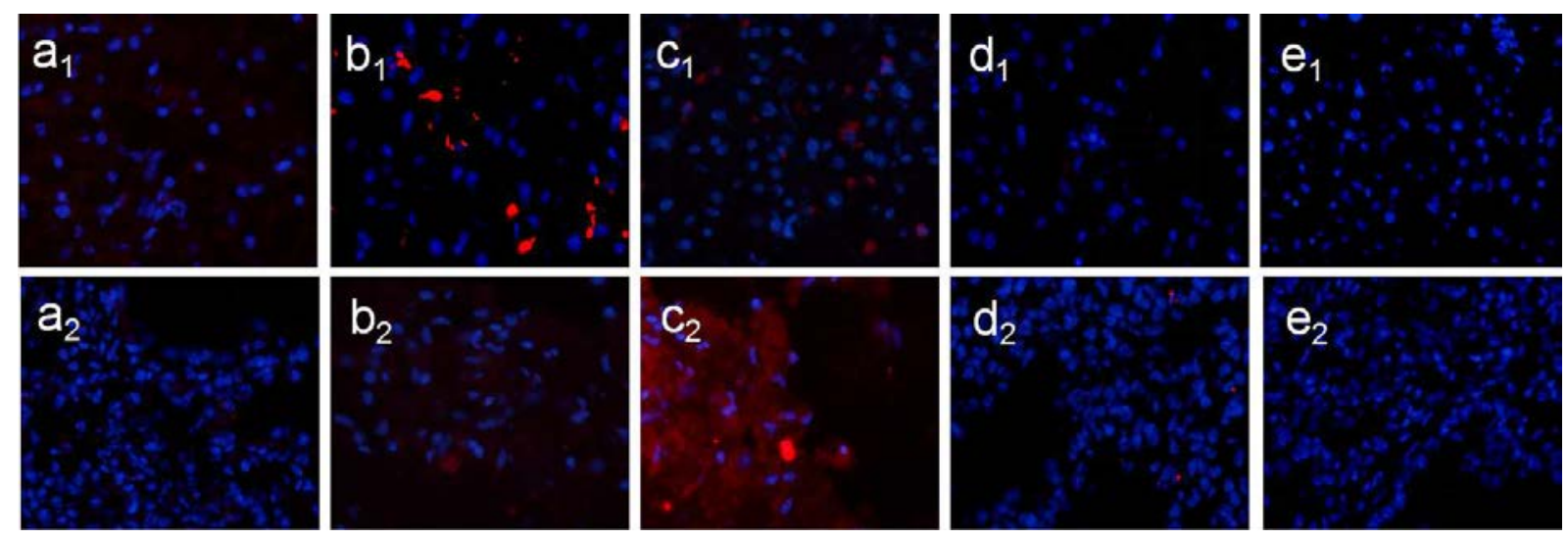

Figure S12. Immunofluorescence of DOX fluorescence after i.v. Injection of (a) PBS;

(b) DOX; (c) DOX@MSN; (d) DOX@IMSN and (e) DOX@HIMSN among various organs. (1. liver; 2. lung) 


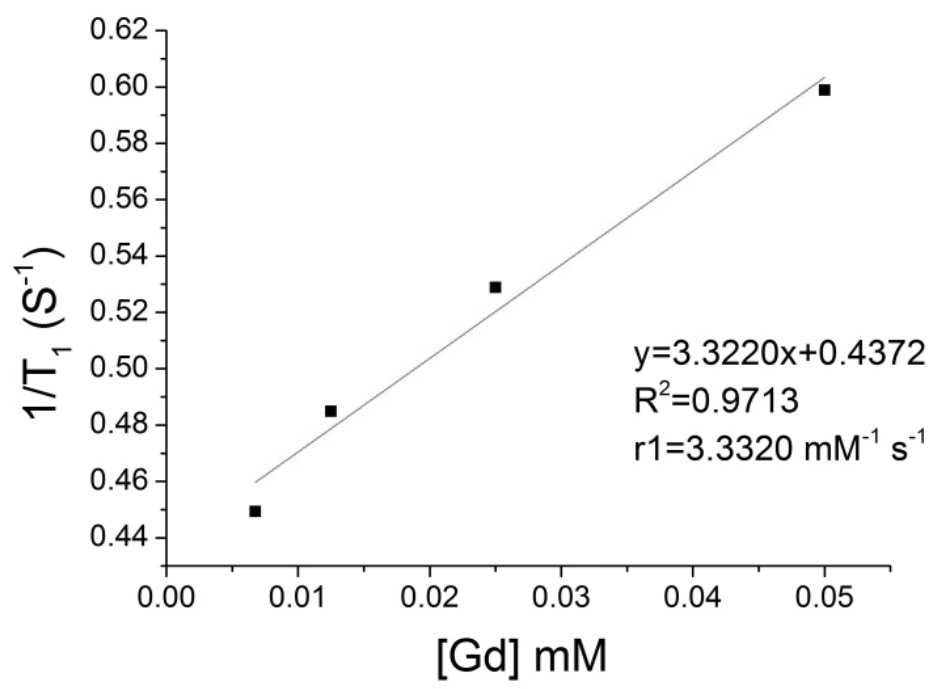

Figure S13. In vitro relaxation rate of DOX@HIMSN. 


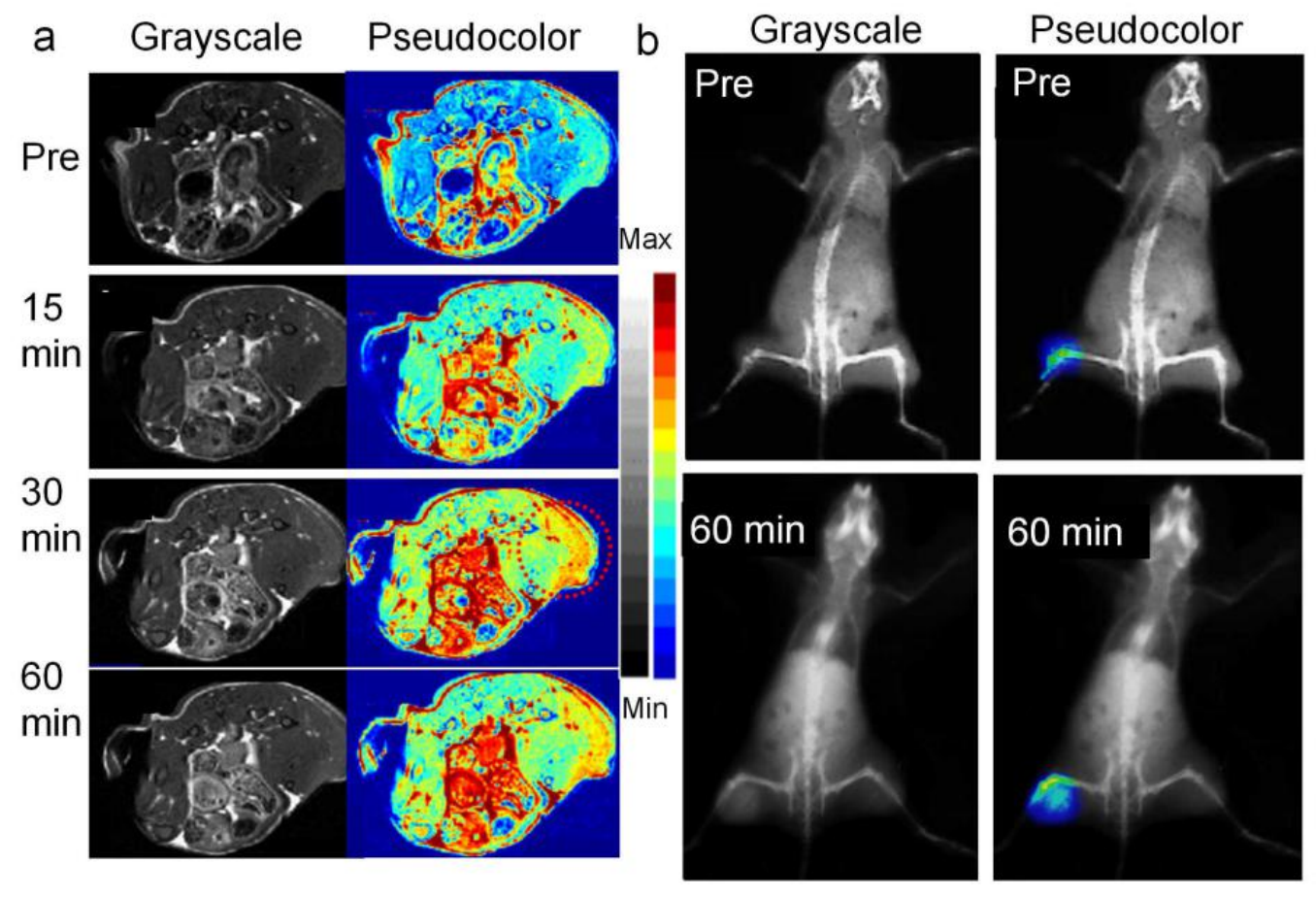

Figure S14. In vivo (a) MRI imaging and (b) CT imaging after the injection of DOX@HIMSN with pseudocolor processing. 

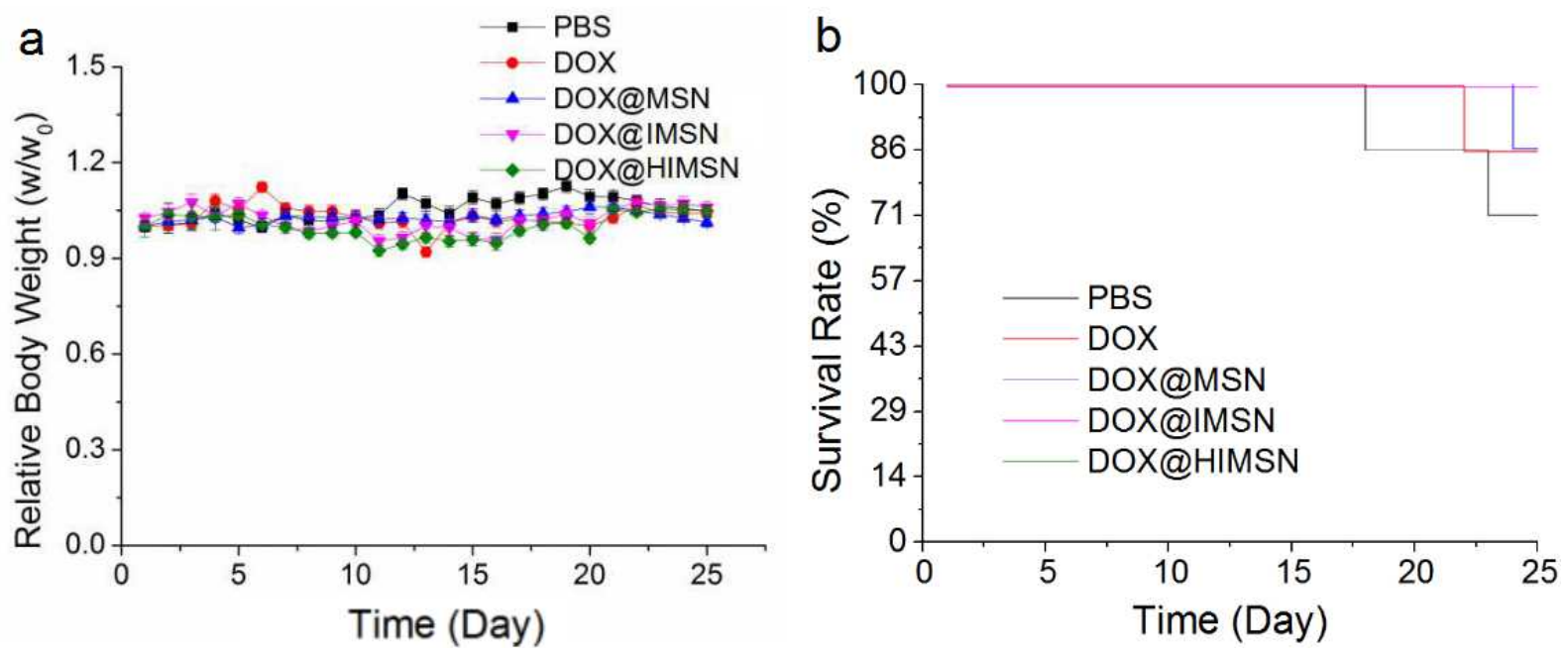

Figure S15. (a) Relative body weight of 4T1 tumor bearing mice after the treatment of PBS, free DOX, DOX@MSN, DOX@IMSN and DOX@HIMSN; (b) Survival rate of 4T1 tumor bearing mice after the treatment of PBS, free DOX, DOX@MSN, DOX@IMSN and DOX@HIMSN. 


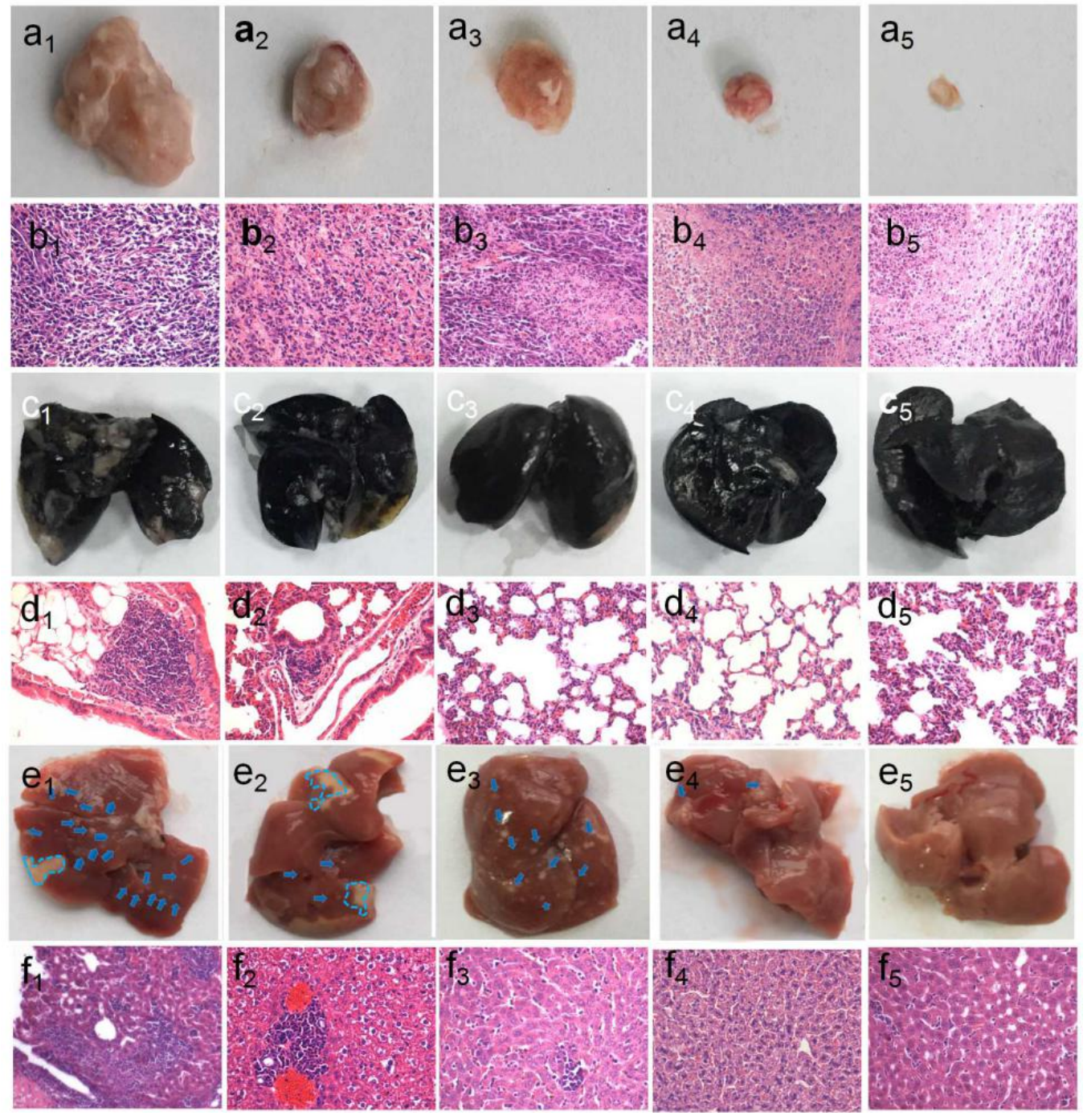

Figure S16. Representative (a) images and (b) H\&E staining of tumors at the 25th day. Representative (c) images and (d) H\&E staining of lungs at the 25th day. Representative (e) images and (f) H\&E staining of livers at the 25th day. (1: PBS group; 2: DOX group; 3: DOX@MSN group; 4: DOX@MSN group; 4: DOX@HIMSN group). 

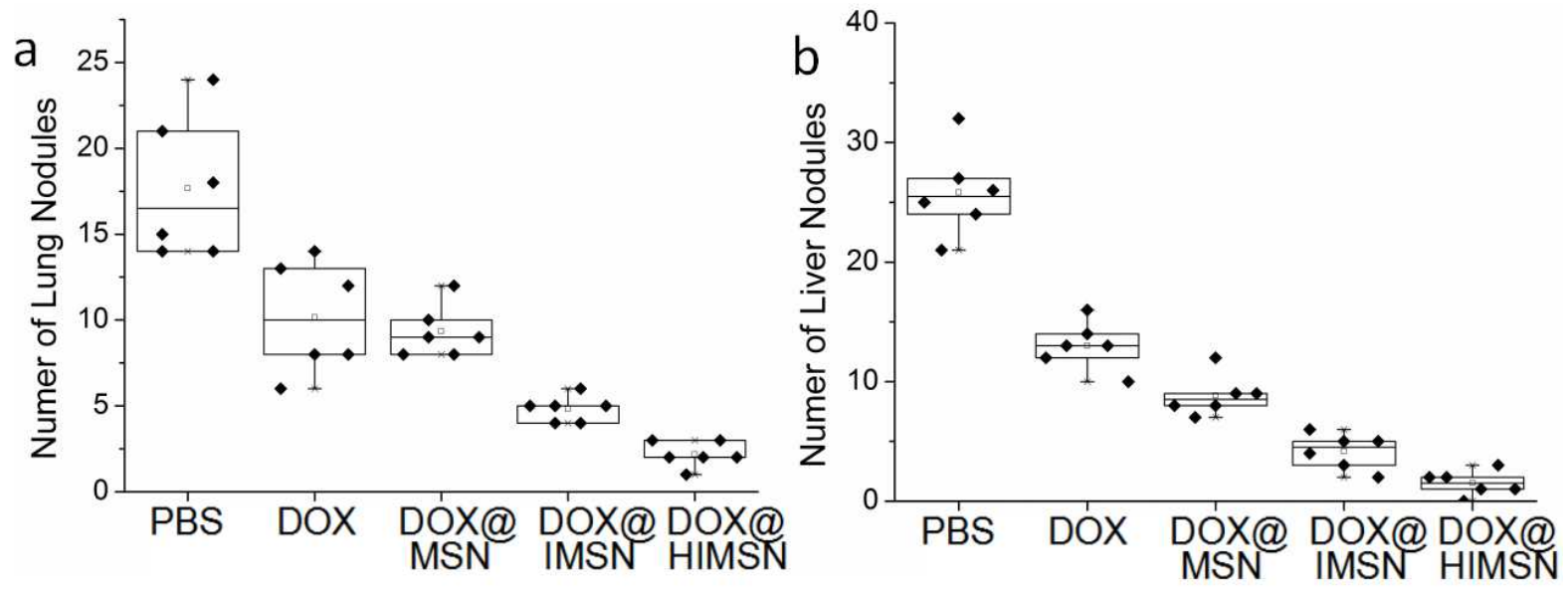

Figure S17. Quantitative study of lungs and livers metastasis. (a) Box plot of lung nodules. (b) Box plot of liver nodules. 

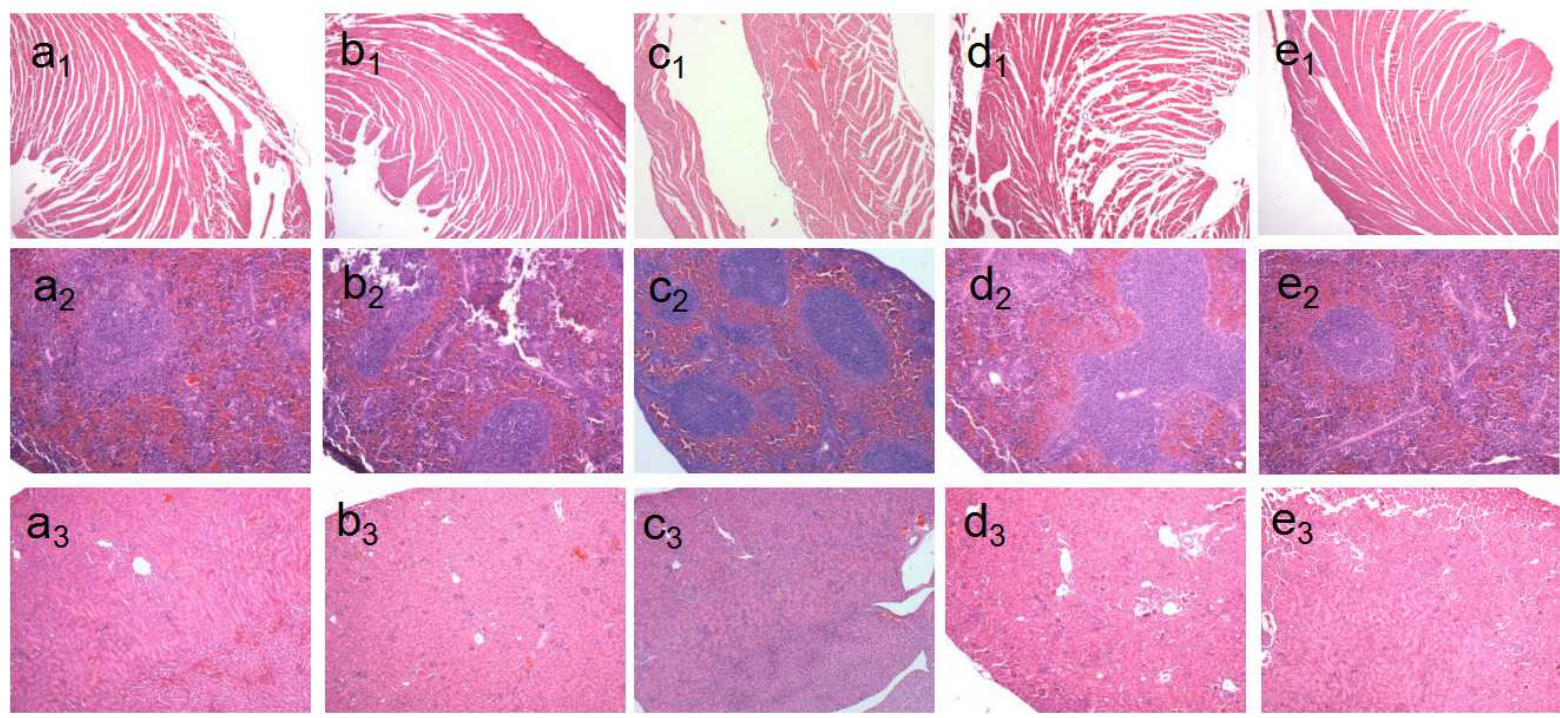

Figure S18. H\&E staining of 1.heart; 2.spleen and 3. kidney after i.v. injection of (a) PBS; (b) DOX; (c) DOX@MSN; (d) DOX@IMSN and (e)DOX@HIMSN. 

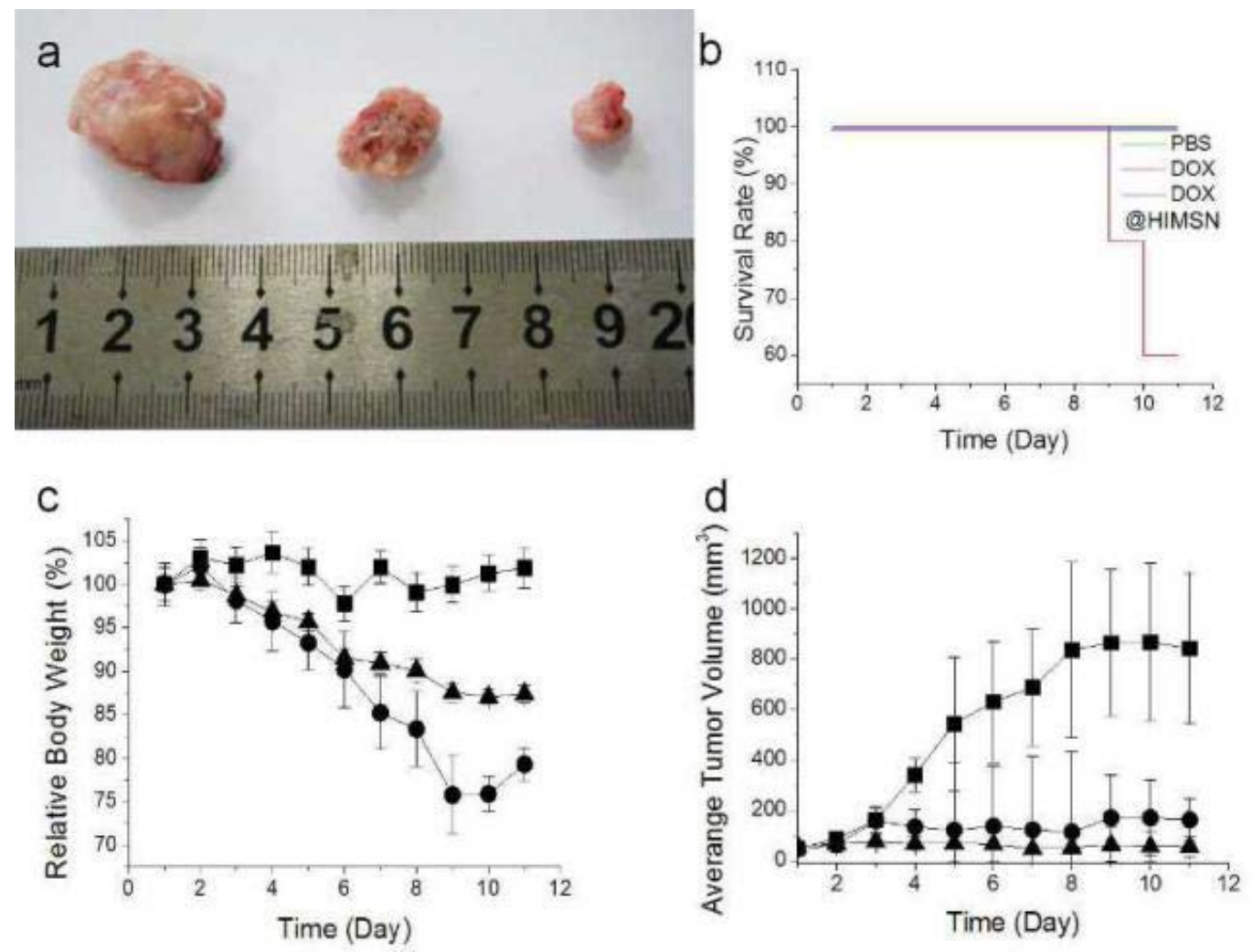

Figure S19. In vivo anti-cancer study of DOX@HIMSN via subcutaneous injection once every two days. (a) Representative images of the tumors at the 12th day post-treatment. (b) Survival rate of mouse with different treatment. (c) Average tumor volume curve with different treatment (ロ PBS, • DOX and $\Delta$ DOX@HIMSN). (d) In vivo relative body weight curve with different treatment PBS, - DOX and $\boldsymbol{\Delta}$ DOX@HIMSN). 

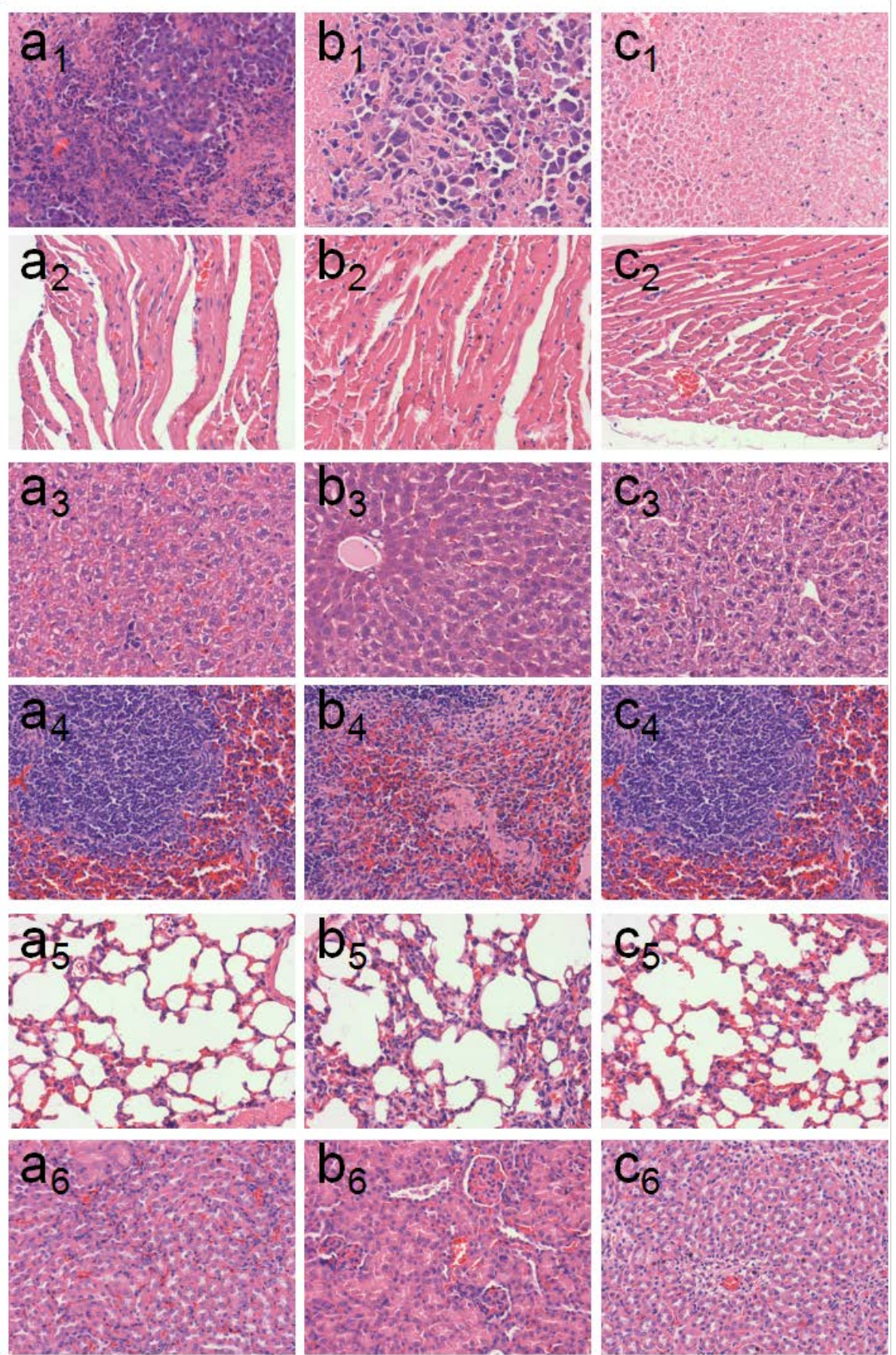

Figure S20. H\&E staining images of tissues after s.c. injection of (a) PBS, (b) DOX and (c) DOX@HIMSN. Image 1: tumor; Image 2: heart; Image 3: liver; Image 4: spleen; Image 5: lung; Image 6: kidney (×200). 


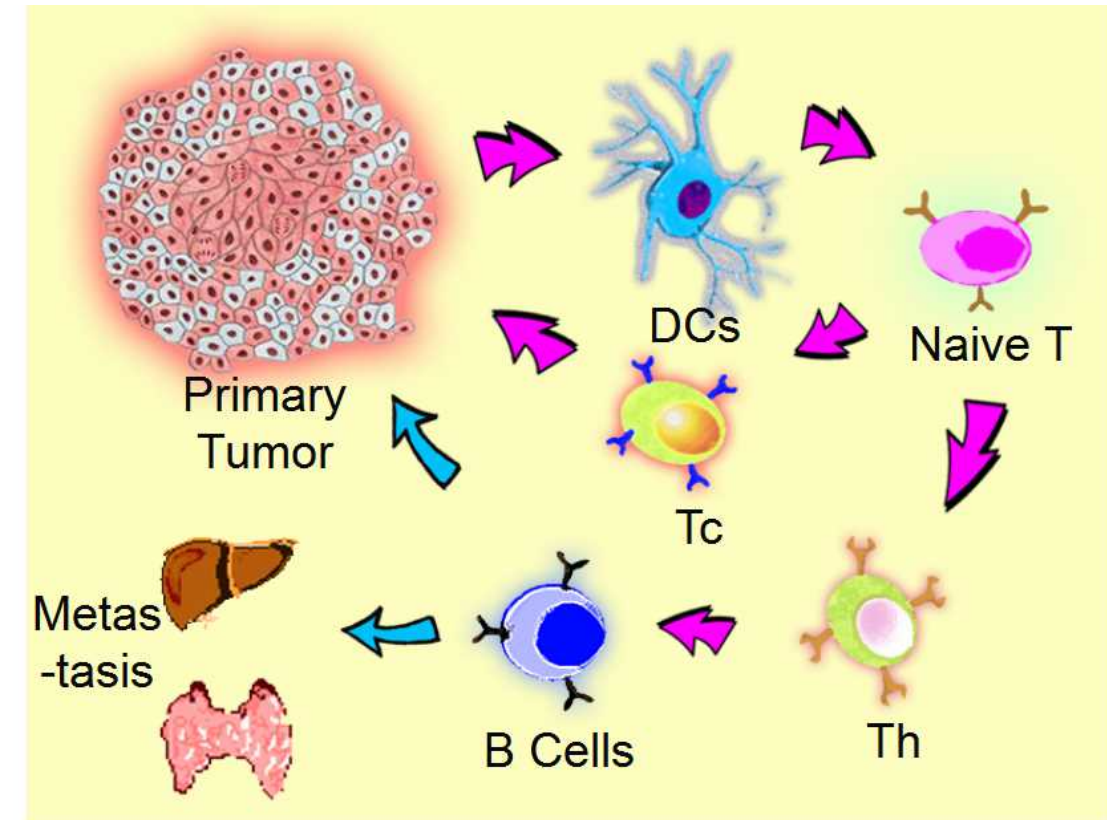

Figure S21. DOX kills the cancer cells and leads to an antigen release. Then, the professional antigen-presenting cells (APC), such as DCs effectively stimulates T cells triggered anti-tumor immune responses with antigen cross presentation. Then $\mathrm{CD}^{+}$killer T cells, also known as cytotoxic $\mathrm{T}$ (Tc) cells are recruited to kill the tumor cells. At the same time, $\mathrm{CD} 4^{+}$helper $\mathrm{T}(\mathrm{Th})$ cells activated the $\mathrm{CD} 19^{+} \mathrm{B}$ cells, which are able to work together with $\mathrm{CD} 8^{+} \mathrm{T}$ cells to promote the adaptive immunities. 


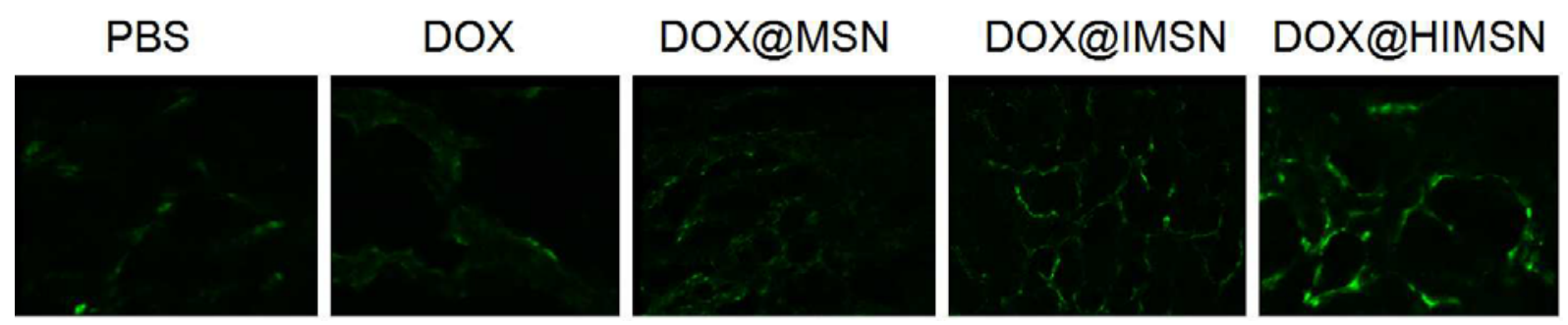

Figure S22. Caspase-3 stained (green light) tumor tissues after PBS, DOX, DOX@MSN, DOX@IMSN and DOX@HIMSN treatment. 


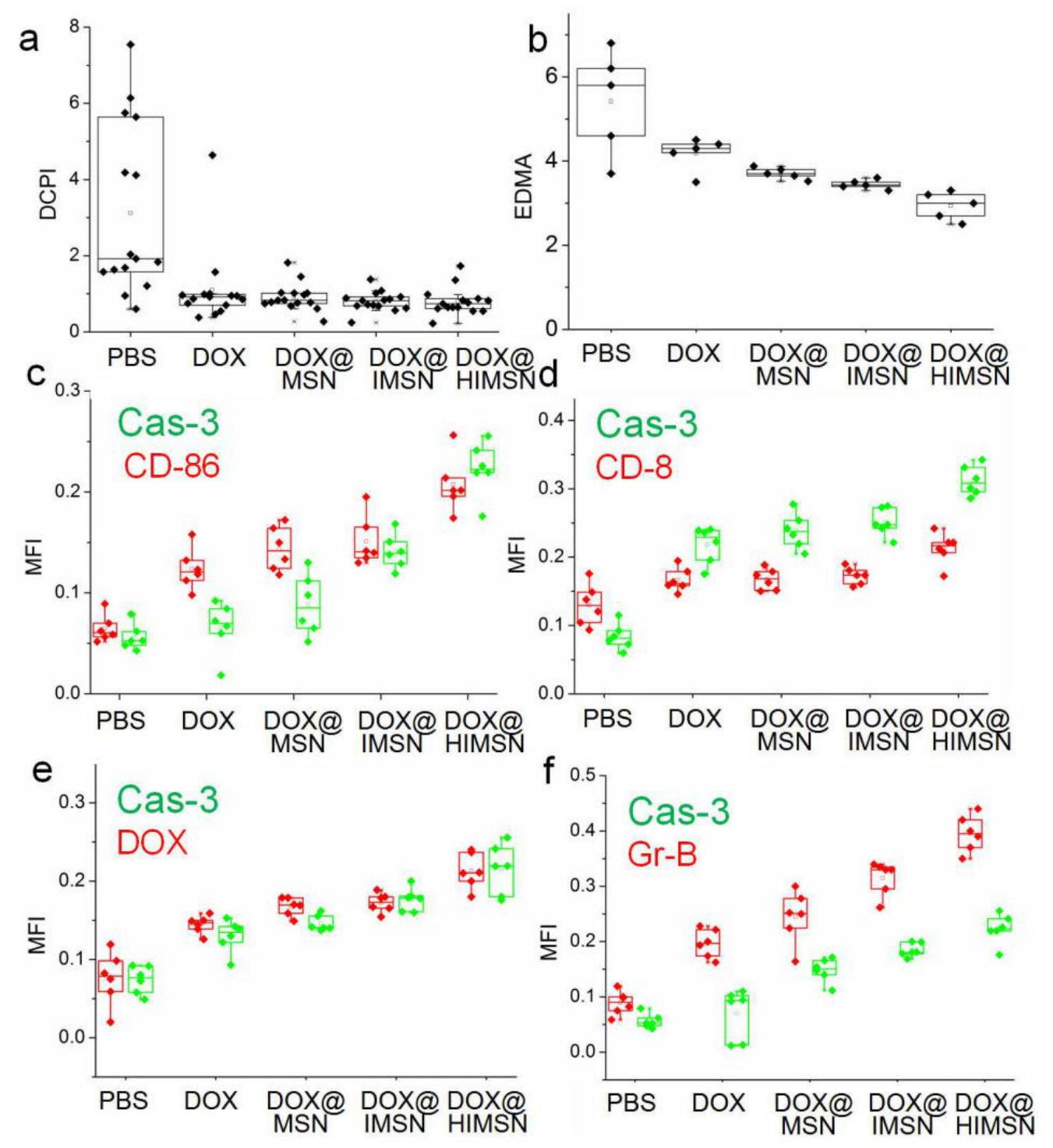

Figure S23. In vivo quantitative study of (a) dead-cell proximity index of CD-86/caspase-3; (b) Euclidean distance matrix analysis of CD-86/caspase-3; (c) CD-86/caspase-3 levels; (d) CD-8/caspase-3 levels; (e) DOX/caspase-3 levels and (f) granzyme-B/caspase-3 levels after PBS, DOX, DOX@MSN, DOX@IMSN and DOX@HIMSN treatments. (DCPI: dead-cell proximity index; EDMA: Euclidean distance matrix analysis; MFI: mean fluorescence intensity) 


\section{References}

1. Vacchelli, E.; Ma, Y.; Baracco, E. E.; Sistigu, A.; Enot, D. P.; Pietrocola, F.; Yang, H.; Adjemian, S.; Chaba, V.; Peschiaroli, F.; Businaro, L.; Gerardinio, A.; Manic, G.; Ulas, T.; Günther, P.; Schultze, J. L.; Kwpp, O.; Stoll, G.; Lefebvre, C.; Mulot, C.; Castoldi, F.; Rusakiewicz, S.; Ladoire, S.; Apetoh, L.; Pedro, J. M. B-S.; Lucattelli, M.;

Delarasse, C.; Boige, V.; Ducreux, M.; Delaloge, S.; Borg, C.; André, F.; Schiavoni, G.; Vitale, I.; Lautent-Puig, P.; Mattei, F.; Zitvogel, L.; Kroemer, G. Science 2015, 350, 972-978.

2. Pavani, S. R. P.; Thompson, M. A.; Biteen, J. S.; Lord, S. J.; Liu, N.; Twieg, R. J.; Piestun, R.; Moerner, W. E. Proc. Natl. Acad. Sci USA. 2009, 106, 2995-2999.

3. Han, J. M.; Jeong, S. J.; Park, M. C.; Kim, G.; Kwon, N. H.; Kim, H. K.; Sang, H. H.; Sung, H. R.; Kim, S. Cell, 2012, 149, 410-424.

4. Xiang, J.; Xu, L.; Gong, H.; Zhu, W.; Wang, C.; Xu, J.; Feng, L.; Cheng, L.; Peng, R.; Liu, Z. ACS Nano 2015, 9, 6401-6411.

5. Restifo, N. P.; Dudley, M. E.; Rosenberg, S. A. Nat. Rev. Immunol. 2012, 12, 269-281. 